\title{
PASADO, PRESENTE Y FUTURO DE LA OBJECIÓN DE CONCIENCIA AL SERVICIO MILITAR EN ESPAÑA
}

\author{
JOAN OLIVER ARAUJO
}

Catedrático de Derecho Constitucional

Universidad de las Islas Baleares 



\title{
PASADO, PRESENTE Y FUTURO DE LA OBJECIÓN DE CONCIENCIA AL SERVICIO MILITAR EN ESPAÑA $(*)$
}

POR

\author{
JOAN OLIVER ARAUJO \\ Catedrático de Derecho Constitucional \\ Universidad de las Islas Baleares
}

\section{EL PASADO DE LA OBJECIÓN DE CONCIENCIA AL SERVICIO MILITAR}

Aunque nuestra historia constitucional $-y$ con ella la larga marcha por las libertades-se inició a principios del siglo pasado, durante todo el siglo $x \mid x$ y la primera mitad del siglo $x \times$ no se planteó, en términos mínimamente significativos, el tema de la objeción de conciencia al servicio militar. Como afirma el profesor Cámara Villar, ninguna de nuestras Constituciones históricas ni ninguna de las leyes ordinarias de desarrollo de las mismas sintió la necesidad de reflejar el problema de la objeción de conciencia en su articulado, "sencillamente porque no se había planteado todavía en la sociedad".

(*) Una parte de este trabajo ya ha sido publicada en dos opúsculos: De nuevo sobre la objeción de conciencia al servicio militar, Centro de Estudios Constitucionales («Cuadernos y Debates», Serie Minor, núm. 5), Madrid, 1996 (gracias a la gentileza del profesor Luis Aguiar de Luque); y Libertad de conciencia y servicio militar, Institut de Ciències Polítiques i Socials -adscrit a la Universitat Autònoma de Barcelona- (Colección Working Papers, núm. 116), Barcelona, 1996 (gracias a la amabilidad del profesor Isidre Molas). 
Con carácter esporádico puede encontrarse en los debates constituyentes que precedieron a la Constitución nonnata de 1856, a la Constitución de 1869 y a la Constitución de 1931 alguna intervención que aludía, de modo incidental y casi siempre crítico, a la actitud de los miembros de ciertas confesiones no católicas - principalmente los cuáqueros-que invocaban objeción de conciencia al servicio militar y al pago de impuestos (Peláez Albendea). Pero se trataba de una actitud tan excepcional que, en ningún momento, se planteó, ni siquiera remotamente, la posibilidad de estudiar $y$, menos aún, reglamentar este fenómeno.

Durante la Guerra Civil Española son conocidos dos casos de objeción de conciencia que se produjeron en la zona republicana. En concreto, en 1937, el catalán Ramón Serrano y el aragonés Nemesio Orús se negaron a empuñar e incluso a tocar las armas. Ambos fueron condenados por un tribunal militar.

En España, la objeción de conciencia al servicio militar como fenómeno con alguna relevancia social no comienza a producirse hasta finales de los años cincuenta del presente siglo. Para analizar el difícil proceso histórico que atraviesa en nuestro país la objeción de conciencia, desde su tipificación como delito castigado con severidad hasta su consagración como derecho constitucional fuertemente garantizado, vamos a estudiar tres fases: 1.a) La situación de los objetores de conciencia hasta la aprobación de la Ley 29/1973, de 19 de diciembre (que se corresponde con la etapa de las denominadas "condenas en cadena"). 2..") La fase que se inicia con la entrada en vigor de la Ley $29 / 1973$, de 19 de diciembre, que introduce el artículo 383 bis en el Código de Justicia Militar. 3.9) La fase en la que se aplica el Real Decreto $3.011 / 1976$, de 23 de diciembre, que regula las prórrogas de incorporación a filas por objeción de conciencia de carácter religioso. A continuación, intentando armonizar los aspectos jurídicos con los de índole política, analizaremos estos tres períodos, tras lo cual estaremos en condiciones de iniciar el estudio de la objeción de conciencia al servicio militar en España en la actualidad. 


\section{A) La situación de los objetores de conciencia hasta la aprobación de la Ley 29/1973, de 19 de diciembre: las «condenas en cadena»}

En España, el fenómeno de la objeción de conciencia al servicio militar tiene sus primeras manifestaciones públicas a finales de los años cincuenta del presente siglo, cuando varios ciudadanos pertenecientes a la comunidad religiosa de los Testigos de Jehová se negaron abiertamente a empuñar las armas. Los primeros casos fueron los de Jesús Martín Nohales (en 1958) y Alberto Contijoch Berenguer (en 1959), pero a partir de estas fechas los casos de objeción de conciencia de testigos de Jehová que eran llamados a filas se fueron reproduciendo en todas las provincias españolas. Los testigos de Jehová en edad militar que no salieron de España en la década de los sesenta dieron un fuerte testimonio de coherencia con sus creencias. "Contijoch recuerda el caso de varios compañeros suyos destinados a realizar el servicio militar en Lérida, que fueron torturados para forzarles a realizar la mili. Muchos fueron apaleados e incluso amenazados de violación si se negaban a realizar servicios auxiliares. Uno de los casos más horripilantes se dio en 1964, cuando el testigo de Jehová Juan Tomás Goparra, tras recibir diversas palizas, fue atado desnudo en el suelo de la cuadra, soltándose luego a las mulas, a las que se azuzaba para que lo pisaran" (Xavier Rius). El mismo Contijoch sufrió numerosas palizas y tratos inhumanos y degradantes, entre ellos podemos destacar el que tuvo lugar en Palma de Mallorca, cuando permaneció cuarenta y cinco días en calzoncillos en el calabozo, ya que le habian arrebatado la ropa civil. Pero esto no era todo. Si el trato que recibían en los cuarteles era el que acabamos de describir, el que recibieron por parte de los hombres de Derecho no era tampoco demasiado correcto. Así, Quintano Ripollés afirmaba que la objeción de conciencia era una postura "extravagante", y el propio Tribunal Supremo, en la Sentencia de 15 de noviembre de 1965, la calificaba de "concepto disolvente".

La situación de los objetores en España dio un salto cualitativo en enero de 1971, cuando apareció el primer objetor de conciencia católico: José Luis Beúnza Vázquez. En efecto, en esta fecha Pepe Beúnza se declaró objetor de conciencia católico, noviolento y pacifista, siendo condenado por un consejo de guerra y encarcelado. En este caso se daban tres circunstancias particulares que le dieron un especial relieve: era el primer objetor de conciencia católico (lo que provocó que numerosas asociaciones y sectores cristianos le manifestaran su solidaridad; así, por ejemplo, la Asociación Pax Christi le otorgó el "Memorial Juan XXIII»), era el primer objetor que contaba con una estruc- 
tura de apoyo preparada con anterioridad, y era el primer objetor que expresamente se ofrecia para realizar un servicio civil sustitutorio del militar (Xavier Rius). El encarcelamiento de Pepe Beúnza fue el detonante para que el problema de la objeción de conciencia alcanzara una considerable trascendencia pública, poniendo sobre el primer plano de la actualidad un problema que hasta entonces había estado aletargado. Desde el momento en que entró en la cárcel, se inició una intensa campaña nacional e internacional para pedir su libertad y, por extensión, la de todos los españoles encarcelados por ser objetores de conciencia al servicio militar. Entre las numerosas manifestaciones que se sucedieron, podemos recordar - por su trascendencia internacional- las que tuvieron lugar en Nueva York, París y Londres. Asimismo, se llevó a cabo una marcha de más de setecientas personas que, comenzando en Ginebra, debía finalizar en la prisión de Valencia; aunque en la frontera franco-española fueron detenidos los participantes españoles y se impidió el paso a los demás, el objetivo de llamar la atención de la opinión pública internacional ya se había conseguido. El gesto de Pepe Beúnza tuvo, como hemos dicho, una honda repercursión social, $y$, muy pronto, fue seguido por otros jóvenes católicos (entre ellos podemos recordar a Víctor Boj, Jordi Agulló y Juan Guzmán). Como afirmó, poco después, el procurador en Cortes ultraconservador Blas Piñar López, "la actitud humilde de los testigos de Jehová se convierte en los católicos en una actitud subversiva».

Cuando comenzaron a producirse abiertamente las primeras actitudes objetoras de conciencia al servicio militar, la respuesta de las autoridades militares $y$ del régimen franquista en general fue reprimirlas con dureza como escarmiento y para evitar, de este modo, que se multiplicaran. El fundamento "constitucional" de esta represión lo encontraban en el artículo 7 del Fuero de los Españoles de 1945, cuando decía: "Constituye título de honor para los españoles el servir a la Patria con las armas. Todos los españoles están obligados a prestar este servicio cuando sean llamados con arreglo a la ley". Por tanto, el cumplimiento del servicio militar era obligatorio y general, $y$ la negativa a prestarlo debía ser castigada. Sin embargo, sentada esta declaración de principios, era preciso concretar un elemento de orden procesal y otro de orden penal. El primero era determinar cuál era la jurisdicción 
competente para conocer y castigar la negativa a cumplir el servicio militar; $y$ el segundo era precisar dentro de qué figura delictiva se iba a incluir esta negativa a empuñar las armas.

En cuanto al primer tema, esto es, determinar cuál era el orden jurisdiccional competente para conocer de esta materia, el Tribunal Supremo declaró que correspondía a la jurisdicción castrense por dos motivos. En primer lugar, porque la persona que se negaba a cumplir el servicio de armas ya era - a estos efectos- un militar en servicio activo (en este sentido, recordaba que la normativa sobre reclutamiento sometía a la jurisdicción militar a los llamados a filas desde el momento de su ingreso en Caja). En segundo lugar, consideraba que la jurisdicción competente era la militar porque los hechos que se imputaban no constituían un delito de propaganda ilegal tipificado en el Código Penal ordinario, sino un delito de desobediencia a las órdenes de un superior previsto en el Código de Justicia Militar (García Arias).

La segunda cuestión, esto es, determinar dentro de qué figura delictiva se iba a incluir la negativa a cumplir el servicio militar, tampoco estaba exenta de problemas, pues el legislador español no había tipificado penalmente esta negativa. Ante este vacío normativo, la jurisdicción militar española consideró - bastante forzadamente- que el objetor de conciencia incurría en un delito de desobediencia a las órdenes de un superior previsto en el artículo 328 del Código de Justicia Militar, en su modalidad de órdenes no relativas al servicio de armas. En consecuencia, el objetor de conciencia al servicio militar era castigado a una pena de prisión militar que oscilaba entre los seis meses y un día y los seis años. Pero esto no era todo. Una vez cumplido el tiempo de la pena privativa de libertad, no quedaban exentos del servicio militar, sino que eran vueltos a llamar a filas, y si volvían a negarse - que era lo normal- incurrían otra vez en el mismo delito de desobediencia, y por segunda vez eran encausados y condenados; e igualmente sucedía una tercera, e incluso en posteriores ocasiones, hasta que cumplían los treinta y ocho años, edad en la cual se pasaba a la situación de licencia absoluta. Esta imposición de "condenas en cadena" daba lugar a lo que ciertos autores de la época calificaron de "prisión vitalicia». El profesor Martín-Retortillo, con la brillantez y el apasionamiento que caracteriza a muchos de sus trabajos, ha descrito con precisión la "diabólica" situación que se vivía con estas palabras: "Tras la inicial condena - con pena que iba de seis meses y un día a seis añospodían enganchar sucesivas condenas, pues una vez cumplida la primera volvían a ser llamados al servicio militar. La nueva negativa daba pie a la ulterior sanción, y así, eslabón tras eslabón, se iba trenzando la 
diabólica cadena que podía alargarse hasta el cumplimiento de la edad de licencia absoluta, fijada entonces en los treinta y ocho años".

Aunque en alguna ocasión el abogado defensor de los objetores encarcelados intentó, para evitar las sucesivas condenas en cadena, que se aplicara en estos casos el delito continuado de desobediencia, obtuvo una respuesta negativa del Consejo Supremo de Justicia Militar. Este Alto Tribunal, en su Auto de 14 de octubre de 1960, afirmó que aunque las sucesivas negativas de una misma persona reúnen «algunas de las características de ejecución del delito continuado, como son las de unidad de propósito, de bien jurídico lesionado, de ley violada y de sujeto pasivo, es evidente que la instrucción de un nuevo procedimiento interrumpió la posible comunicación entre los dos grupos de infracciones de la misma índole, y no existe, por lo tanto, entre ellas, el vínculo de unidad que permita subsumirlas en una sola figura delictivan. En otros casos posteriores, las defensas alegaron las eximentes de estado de necesidad y de obrar en el cumplimiento de un deber, la atenuante de obrar por motivos morales de notoria importancia y, a partir de 1967, la Ley de Libertad Religiosa; prácticamente todo fue inútil, pues no se consiguió - en términos generales- mitigar la dureza de la jurisdicción militar (Sánchez González y Llamazares Fernández).

Las "condenas en cadena" que se aplicaban a los objetores de conciencia suponian, como hemos dicho, su encarcelamiento hasta que cumplían los treinta y ocho años de edad. Un castigo absolutamente escandaloso que incluso podía superar con facilidad los que se imponían por delitos de sangre. "La situación de los objetores españoles era tan deplorable e injusta que trascendió fuera de nuestras fronteras, de manera que la opinión pública internacional y las instituciones europeas, como el Consejo de Europan, presionaron al Gobierno español para que mejorara el tratamiento jurídico que se daba a sus ciudadanos que se negaban a empuñar las armas. Con todo, hasta 1973, como veremos, "no se produjo un tímido e insuficiente cambio legal» en la reglamentación de las consecuencias de la actitud objetora (Ramón Soriano).

De la dureza del trato que recibían aquellos jóvenes españoles que se negaban a cumplir el servicio militar, dan testimonio algunos trabajos de la época. Así, en 1966, el catedrático de Derecho Internacional Luis García Arias publicó el artículo titulado "Servicio militar y objeción de conciencian, en el cual -aun afirmando que la objeción de conciencia era inadmisible y que, a su juicio, debía seguir siendo una actitud sancionada penalmente - abogaba por humanizar la legislación española para evitar las condenas en cadena. En su opinión, y es 
importante recogerla porque es la que asumirá posteriormente la Ley de 19 de diciembre de 1973, esta humanización podría lograrse mediante la introducción de una nueva norma que tipificase expresamente el delito de negarse a cumplir el servicio militar y su correspondiente sanción; de este modo, el cumplimiento de la condena que se le impusiera -siempre por un tiempo superior que el que los de su reemplazo cumplieran en el servicio militar- cancelaria su deuda con la sociedad, sin que, al ser liberado, se le exigiera otra prestación. Esta propuesta "humanitaria", aunque ahora nos parezca absolutamente insuficiente y criticable, era, en aquellos momentos y dentro de un sistema fuertemente autoritario, una tesis relativamente avanzada, que de haberse recogido rápidamente hubiera podido reducir el período de cárcel de numerosos testigos de Jehová. Garcia Arias, que tuvo el coraje de lanzar esta propuesta de modificación legislativa en una conferencia que pronunció en el Consejo Supremo de Justicia Militar, buscó apoyo en los documentos del Concilio Vaticano II, recordando, en concreto, el deber impuesto a los Estados de tratar "con sentido humano" a quienes se nieguen a tomar las armas por motivo de conciencia ( $G a u$ dium et Spes, núm. 79).

Algunos años más tarde, y con una finalidad muy distinta, Jesús Jiménez publicó el libro titulado La objeción de conciencia en España, que causó un gran impacto y consiguió rápidamente una amplia difusión. Este autor, además de analizar la situación de los objetores de conciencia en nuestro país, dio a conocer los nombres y apellidos de los jóvenes que en aquel preciso momento -febrero de 1973- estaban encarcelados por este motivo; también informó de las causas instruidas, su número de identificación, la fecha de las condenas, la duración de las mismas y el lugar de su cumplimiento. El total de ciudadanos encarcelados ascendía a 268 , de los cuales 264 eran testigos de Jehová y 4 católicos; algunos testigos de Jehová estaban encarcelados desde 1962, y setenta y dos ya llevaban más de cinco años en prisión en la fecha indicada (Foraster Serra).

La situación que padecían los objetores de conciencia españoles era, como hemos repetido, de extrema dureza. Con ella, el régimen pretendía hacerles desistir de su actitud y, de esta manera, evitar el "contagio". Sin embargo, el número de testigos de Jehová que se ne- 
gaban a empuñar las armas invocando una objeción de conciencia de carácter religioso iba aumentando año tras año. A partir de mediados de la década de los sesenta, como afirma Xavier Rius, "los militares asumieron ya a los testigos como una carga irremediablen. Aceptada, pues, la situación de hecho de que cierto número de españoles no abandonarían su actitud contraria a empuñar las armas por duras que fueran las condenas que se les impusieran, ciertos sectores moderados del propio franquismo propusieron la búsqueda de una salida legislativa que evitara la monstruosidad de las condenas en cadena, que mantenía a los objetores en prisión hasta que cumplian los treinta y ocho años de edad. Sin embargo, estos sectores moderados del régimen que buscaban algún tipo de arreglo, no lo hacían principalmente por benevolencia y humanidad, sino que, por el contrario, estaban movidos por claros motivos políticos que, a continuación, vamos a analizar brevemente:

1. ${ }^{\circ}$ La fuerte presión de la opinión pública internacional y de algunas instituciones europeas para que se mitigara el rigor con que la legislación española trataba a los objetores de conciencia

Esta presión internacional aumentó sensiblemente a partir de 1969, cuando un periodista del rotativo inglés The Guardian, aprovechando una ceremonia que se celebraba en el penal gaditano de Santa Catalina (donde se encontraban encarcelados por objeción de conciencia 150 testigos de Jehová), entró mezclado entre los familiares de los presos y realizó un amplio informe con fotografías, que posteriormente vendió a la agencia de noticias Reuter. Esto permitió que la problemática de los testigos de Jehová españoles se difundiera en toda la prensa mundial. Acto seguido, se produjeron numerosas manifestaciones en el extranjero y la interrupción del paso de algunos trenes españoles fuera de nuestro territorio. Amnistía Internacional también presionó al Gobierno español, pero fue el Consejo de Europa el organismo que preparó el documento más concreto. Nos estamos refiriendo a la "Proposición de Resolución relativa a la situación de los objetores de conciencia en España», presentada por el Consejo de Europa en Estrasburgo el 22 de enero de 1971. En ella se lamentaba «la severidad extraordinaria con la cual el Derecho español amenaza a los elementos de su juventud que reclaman la objeción de conciencian; se recordaba la Resolución 337, de 26 de enero de 1967, de la Asamblea Consultiva del Consejo de Europa, relativa al derecho a la objeción de conciencia; 
y se deseaba que «el Gobierno español tome las medidas propias para establecer un estatuto de los objetores de conciencia preveyendo un servicio civil sustitutivon, con la esperanza de solucionar 0 , al menos, paliar la penosa situación de los objetores encarcelados.

2. ${ }^{\circ}$ La influencia que ejerció, en un Estado formal y sustancialmente confesional católico como el español, la concreta referencia a la objeción de conciencia contenida en la Constitución Pastoral "Gaudium et Spes" aprobada por el Concilio Vaticano II

Recordemos que en este documento conciliar se afirmaba literalmente: "También parece razonable que las leyes tengan en cuenta, con sentido humano, el caso de los que se niegan a tomar las armas por motivo de conciencia, siempre que acepten al mismo tiempo servir a la comunidad humana de otra forma" (núm. 79). Tras el Concilio, el Papa Pablo VI manifestó en diversas ocasiones su satisfacción por las iniciativas legislativas emprendidas en varios Estados que permitian sustituir el servicio militar obligatorio por un servicio de naturaleza civil. En la misma línea, aunque más tardíamente, la Conferencia Episcopal Española emitió una nota en la que recordaba las resoluciones del Concilio Vaticano II y hacía un Ilamamiento al Gobierno español para que encontrara una solución adecuada. Todos estos documentos y declaraciones surgidas de las más altas instancias de la Iglesia Católica no podian menos que pesar en el ánimo de los gobernantes españoles, sobre todo si se tiene en cuenta que la Ley de Principios del Movimiento Nacional de 1958 - auténtica quintaesencia del régimen-afirmaba que «la Nación española considera como timbre de honor el acatamiento a la Ley de Dios, según la doctrina de la Santa Iglesia Católica, Apostólica y Romana, única verdadera, y fe inseparable de la conciencia nacional, que inspirará su legislación" (principio segundo).

3. ${ }^{\circ}$ La situación conflictiva interna creada por el encarcelamiento de varios centenares de jóvenes, condenados a estar en prisión hasta que cumplieran la edad de treinta y ocho años

Esta situación provocó - dentro de España- manifestaciones, encierros, ayunos y numerosos escritos de protesta de diversas asociaciones y colectivos, sobre todo cuando comenzaron los encarcela- 
mientos de objetores de conciencia católicos: Como botón de muestra, podemos recordar los documentos aprobados por la Junta de la Facultad de Derecho de la Universidad de Valencia y por la Junta Nacional de Colegios de Abogados pidiendo al Gobierno una normativa que permitiera sustituir el servicio militar por un servicio civil (V. Reina Bernáldez y A. Reina Bernáldez).

Todos estos factores provocaron, como hemos dicho, que desde los propios sectores moderados del franquismo se buscara una solución al espinoso problema de la objeción de conciencia. Entendian, con criterio pragmático, que ya que esta actitud se había incrustado en la realidad, la ley debía regularizarla. De este deseo surgieron los dos Proyectos de Ley sobre objeción de conciencia (uno de 1970 y otro de 1971.) que presentó el Gobierno a las Cortes orgánicas. Sin embargo, ninguno de los dos consiguió superar las primeras fases de la tramitación parlamentaria.

Estos intentos de ofrecer una salida legal a los objetores de conciencia - para evitar su encarcelamiento- eran muy restrictivos (sólo admitían los motivos religiosos e imponían un servicio sustitutorio especialmente largo), pero a pesar de ello fueron rápidamente abortados por las Cortes orgánicas. Como afirman los profesores Gascón y Prieto, "los tímidos intentos de comprensión realizados por el Gobierno a comienzos de los años setenta naufragaron ante el escollo inconmovible del militarismo a ultranza de algunos procuradores en Cortes». Éstos, a pesar de tratarse de unos textos extremadamente moderados, los combatieron como si con ellos "se tratara de perpetrar un ataque frontal a las esencias ideológicas del sistema político y social" (Cámara Villar). Algunos parlamentarios orgánicos calificaron a los objetores de conciencia de "traidores", "psicópatas" y "paranoicos trastocados"; y la objeción de conciencia fue calificada de "actitud subversiva" y de "maniobra soviética». Estos fracasos demostraban claramente "hasta qué punto la dura y cerrada mentalidad dominante del régimen se negaba a vislumbrar cualquier posibilidad de cambio en esta materia, $y$ su escasa voluntad de adaptación al Derecho europeo" (Ramón Soriano). 


\section{B) La Ley 29/1973, de 19 de diciembre, que introduce el artículo 383 bis en el Código de Justicia Militar}

Una vez comprobada la imposibilidad de despenalizar en España la objeción de conciencia al servicio militar — dada la cerrazón mental de los procuradores en Cortes-, el Gobierno y el Parlamento decidieron -asumiendo la tesis defendida en 1966 por el profesor Luis García Arias - introducir una nueva norma que tipificase expresamente el delito de negarse a cumplir el servicio militar y su correspondiente sanción. Este nuevo planteamiento, que seguía considerando la objeción de conciencia un delito pero "humanizaba" su castigo, se concretó en la Ley 29/1973, de 19 de diciembre, que introdujo el artículo 383 bis en el Código de Justicia Militar. De acuerdo con este precepto, la negativa a prestar el servicio militar se consideraba un único delito, castigado con la pena de tres años y un día a ocho años de prisión si tenía lugar en tiempo de paz, y con la pena de reclusión mayor si se producía en tiempo de guerra o en territorio declarado en estado de guerra. De este modo, se ponía fin a las sucesivas condenas en cadena, ya que el cumplimiento de la sanción que se le impusiera cancelaría la deuda del objetor con la sociedad; sin que, al ser liberado, se le pudiera exigir otra prestación en tiempo de paz. Como es obvio, y asi lo señalan los profesores Pablo Casado Burbano y Lorenzo Martín-Retortillo, "esta reforma no afrontaba ni resolvía el tema de fondo".

El nuevo artículo 383 bis del Código de Justicia Militar, además de las severas penas privativas de libertad que hemos visto, incorporaba - como accesorias- una amplísima lista de inhabilitaciones para quienes fueran condenados por objeción de conciencia al servicio de armas. Así, mientras no se rehabilitasen, quedaban incapacitados para ejercer los derechos políticos, ostentar cargos y funciones públicas y para establecer relaciones laborales y contractuales de todo orden con entidades públicas; también quedaban incapacitados para la docencia, tanto en el sector público como en el privado, y para obtener el permiso de tenencia y uso de armas. La rehabilitación sólo podía obtenerse mediante el cumplimiento efectivo de las obligaciones militares, que podía solicitarse en cualquier momento desde que se iniciaba el sumario hasta la fecha en que el condenado alcanzaba la edad de la licencia absoluta. Con el fin de animar al desistimiento de su actitud objetora a aquellos que estaban encarcelados por este motivo, este precepto precisaba que cumplido el periodo de servicio en filas se declararía también cumplida la condena de quienes no la hubiesen terminado por incorporarse a aquél antes de su término. 
En síntesis, pues, la principal novedad que introdujo la Ley de 19 de diciembre de 1973 se concretaba en poner fin al sistema de las condenas en cadena, de modo que el cumplimiento de la sanción cancelara la obligación de prestar el servicio militar (salvo en caso de guerra o de estado de guerra). Pero por lo demás, es evidente que la negativa a cumplir el servicio militar se seguía persiguiendo penalmente, por la autoridad militar y con la amenaza de una durísima condena.

\section{C) El Real Decreto 3.011/1976, de 23 de diciembre, que regula las prórrogas de incorporación a filas por objeción de conciencia de carácter religioso}

La primera norma española que reconoció, aunque fuera con grandes limitaciones y cortapisas, la posibilidad de alegar objeción de conciencia al servicio militar sin incurrir en ilícito penal fue el Real Decreto 3.011/1976, de 23 de diciembre, que regulaba las prórrogas de incorporación a filas por objeción de conciencia de carácter religioso. Esta norma, aprobada al comienzo de la transición democrática en un Consejo de Ministros presidido por Adolfo Suárez, mantuvo cierta vigencia durante casi una década.

Se trataba de un texto breve, integrado por seis artículos y una disposición transitoria. En el artículo primero se indicaba que, en aplicación de la facultad concedida en el artículo 364 del Reglamento de la Ley General del Servicio Militar, se establecían prórrogas de incorporación a filas de cuarta clase a), que podían disfrutar los mozos que por razones u objeciones de conciencia, de carácter religioso, se mostrasen opuestos al empleo de las armas y optasen por sustituir el servicio militar en filas por una prestación personal en puestos de interés cívico. Estas prórrogas debían solicitarse en el año del alistamiento, y habían de ser tramitadas antes del quince de agosto de dicho año (art. 2). La Presidencia del Gobierno debia señalar anualmente los puestos de prestación del servicio de interés cívico a los que serían asignados quienes gozasen de las prórrogas por objeción de conciencia, siempre en regiones o zonas militares distintas de la de su residencia (art. 3). Los ciudadanos que obtenian estas prórrogas debian incorporarse a los puestos asignados el primer día hábil del año. Antes del quince de 
agosto del año de prestación del servicio cívico, durante la prórroga, les debía ser extendido un certificado acreditativo de su comportamiento en el puesto asignado, que, de ser favorable, les permitía solicitar una nueva prórroga (art. 4). La prestación del servicio en condiciones favorables por tres períodos consecutivos de un año, permitía obtener la exención del servicio militar activo, pasando a la situación de reserva (art. 5). Finalmente, se establecía que la Presidencia del Gobierno, con el informe de la Junta Interministerial de Reclutamiento, podía dictar las disposiciones complementarias necesarias para la aplicación de este Real Decreto.

El análisis de esta norma nos conduce a realizar los siguientes comentarios:

1.') El Real Decreto 3.011/1976 sólo ofrecia la posibilidad de acogerse a estas prórrogas a quienes se declaraban objetores de conciencia por motivos religiosos, excluyéndose, por tanto, las motivaciones de otra naturaleza (éticas, morales, filosóficas, humanitarias, políticas, etc.). Esta limitación a las objeciones de carácter religioso (incluyendo, no obstante, las de cualquier creencia) tiene, como apuntan los profesores Fernando Amérigo Cuervo-Arango y Lorenzo Martín-Retortillo, una doble explicación: por una parte, la influencia de los dos Proyectos de Ley fallidos sobre objeción de conciencia del tardo-franquismo (el de 1970 y el de 1971), que también contenían esta restricción; y por otra parte, el hecho sociológico indiscutible que «la objeción de conciencia irrumpe entre nosotros como un problema muy ligado al fenómeno religioso" y, más concretamente, a la expansión de la comunidad religiosa de los Testigos de Jehová. A nivel teórico, esta limitación de la eficacia del Real Decreto de 1976 a los objetores de conciencia por motivos religiosos planteaba un problema jurídico de notable importancia. En efecto, si para estos objetores se abría una puerta, para el resto - hasta que se aprobó la Constitución, dos años después- siguió formalmente en vigor el artículo 383 bis del Código de Justicia Militar (incorporado, como sabemos, por la Ley de 19 de diciembre de 1973), que condenaba a los objetores a una pena de tres años y un día a ocho años de prisión si su negativa tenía lugar en tiempo de paz. Sin embargo, en la práctica, durante estos dos años (19771978) la aplicación de este precepto del Código de Justicia Militar quedó absolutamente minimizada.

2..$^{\circ}$ El régimen al que se sometía a los objetores era bastante duro, con el propósito de desaconsejar esta vía y penalizar indirectamente a quienes la siguieran. Esta dureza se advertía, sobre todo, en tres puntos: I) la prestación civil debía cumplirse siempre en regiones 
o zonas militares distintas de la de su residencia; II) la prestación civil sustitutoria duraba tres años; y III) el objetor cada año natural de la prestación era evaluado de su comportamiento en el puesto asignado, y sólo cuando esta evaluación era favorable podía iniciar un nuevo tramo de un año (por tanto, a sensu contrario, una evalución desfavorable le hubiera impedido cumplir los tres años y quedar exento del servicio militar).

A pesar de todas las limitaciones y ambigüedades que acabamos de señalar, el Real Decreto 3.011/1976 representó un importante paso hacia adelante en el intento de buscar una solución satisfactoria para el problema de la objeción de conciencia. Los poderes políticos de la transición democrática hacían, como en tantas otras materias, tanteos dubitativos para enfrentarse con el problema a la búsqueda de una solución (Lorenzo Martín-Retortillo). Así, en el haber de esta norma hay que incluir que, por primera vez en nuestra historia legislativa, entró la expresión urazones u objeciones de conciencia" y, también por vez primera, se ofreció a los objetores por motivos religiosos (en aquellos momentos casi los únicos) un servicio civil alternativo. Teniendo en cuenta el temprano momento de la transición política en que esta norma se aprobó, no podemos menos que valorarla en términos relativamente positivos.

Hasta ahora nos hemos referido a lo que disponían los preceptos que integraban el Real Decreto 3.011/1976, de 23 de diciembre; ahora pasaremos al plano socio-político, para ver cuál fue su aplicación práctica. En este ámbito, lo primero que hay que señalar es que el «servicio de interés cívico" que se preveía en esta norma no llegó a ponerse en práctica, ya que la Presidencia del Gobierno no señaló en ninguna ocasión los puestos en que debía prestarse dicho servicio (Enrique Álvarez Conde). Las razones por las cuales el Real Decreto de 1976 no fue desarrollado hay que buscarlas, posiblemente, en la falta de acuerdo en la concreción de estos puestos de prestación social sustitutoria (Ángela Figueruelo Burrieza), en la abierta oposición al Decreto de importantes colectivos de objetores $y$, sobre todo, en la puesta en marcha de un proceso constituyente que debía resolver el problema de forma definitiva (Antonio Millán Garrido). Como consecuencia de ello, los objetores de conciencia quedaron en una situación de prórroga indefinida, que perduró hasta que entró en vigor la Ley reguladora de la objeción de conciencia dictada en desarrollo del artículo 30.2 de la Constitución. Esta situación -que se amplió rápidamente a los objetores no religiosos y se consumó para todos con la "amnistía" de 1989- provocó una importante discriminación a favor de los objetores de conciencia, pues en 
tanto que éstos se libraron del servicio militar y de cualquier servicio sustitutorio, otros españoles - la inmensa mayoría- en el mismo período temporal cumplieron el servicio militar en filas (V. Reina Bernáldez y A. Reina Bernáldez).

El 17 de octubre de 1977 se publicó en el Boletín Oficial del Estado una amplia amnistía política, que puso en libertad a más de doscientos objetores de conciencia. Con esta medida se resolvía la situación de los objetores encarcelados, pero no la de aquellos que objetaron en los reemplazos siguientes, pues les eran de aplicación el Real Decreto 3.011/1976 y el artículo 383 bis del Código de Justicia Militar, lo que provocó que en las semanas siguientes a aquella amnistía se produjeran nuevos encarcelamientos por negativas a cumplir el servicio militar, bien por estar fundadas en motivos no religiosos o bien por no cumplir los requisitos exigidos en aquel Real Decreto. Para poner fin a esta situación, el Ministro de Defensa - Teniente General Gutiérrez Mellado- dictó la famosa Circular de 23 de noviembre de 1977. conocida entre los objetores como "la orden interna". Esta Circular, bastante anómala pues jamás fue publicada ni en el Boletín Oficial del Estado ni en el Boletín del Ministerio de Defensa, permitía que todos aquellos mozos que alegasen objeción de conciencia quedasen en situación de "incorporación aplazada" y que los soldados que la alegasen una vez incorporados a filas pudieran obtener una "licencia temporal" indefinida. Esta "orden interna" lo que venía a hacer era "congelar" o "aparcar" el problema hasta que se hubiera aprobado la Constitución y dictado las normas legales de desarrollo (Cámara Villar). Con ella, la inmensa mayoría de objetores pudieron negarse a cumplir el servicio militar sin ser por ello perseguidos, aplazándose sine die la solución definitiva. Hubo, sin embargo, algunos objetores no religiosos que tuvieron problemas legales, pues determinadas cajas de reclutas $y$ algunos altos mandos militares con funciones jurisdiccionales no los reconocian como tales, al aplicar literalmente el Real Decreto 3.011/1976, que —como sabemos-circunscribía las prórrogas por objeción de conciencia a aquellos que invocaban un motivo religioso. Algunos de estos casos terminaron ante el Tribunal Constitucional, que les dio una satisfactoria solución transitoria en espera de que se dictase la normativa de desarrollo constitucional. 


\section{EL PRESENTE DE LA OBJECIÓN DE CONCIENCIA AL SERVICIO MILITAR}

Veinte años después de que aparecieran en nuestro país los primeros objetores de conciencia, la Constitución de 1978 intentó sentar las bases para una definitiva solución del problema. Así, su artículo 30, tras afirmar en su primer apartado que "los españoles tienen el derecho y el deber de defender a España", incorpora un segundo apartado con el siguiente tenor: "La ley fijará las obligaciones militares de los españoles y regulará, con las debidas garantías, la objeción de conciencia, así como las demás causas de exención del servicio militar obligatorio, pudiendo imponer, en su caso, una prestación social sustitutorian. Por tanto, por vez primera en nuestra historia, el derecho a la objeción de conciencia, como causa de exención del servicio militar obligatorio, aparece consagrado en un Texto Constitucional. La ley a la que remite el artículo 30.2 fue aprobada, tras una dilatada espera de seis años, a finales de 1984; en concreto, el mandato de este precepto constitucional se cumplió con la Ley 48/1984, de 26 de diciembre, reguladora de la objeción de conciencia y de la prestación social sustitutoria, y con la Ley Orgánica 8/1984, también de 26 de diciembre, por la que se regula el régimen de recursos en caso de objeción de conciencia y su régimen penal.

Debemos añadir, por otra parte, que no se paró en el artículo 30 la preocupación del Constituyente por este tema, ya que en el artículo 53, dedicado a las garantías de los derechos y libertades, se afirma expresamente que el recurso de amparo ante el Tribunal Constitucional "será aplicable a la objeción de conciencia reconocida en el artículo 30 ». Con ello se le otorga la tutela privilegiada ante el Tribunal Constitucional, que está reservada para la protección de los derechos fundamentales.

A pesar de que el artículo 30.2 de la Constitución consagró con rotundidad el derecho a la objeción de conciencia al servicio militar, su desarrollo normativo -impugnado en diversas ocasiones ante la jurisdicción constitucional y ante la jurisdicción ordinaria- ha sido francamente accidentado. Dos leyes aprobadas con gran retraso y fuerte polémica, el recurso de inconstitucionalidad interpuesto por el Defensor del Pueblo, las cuestiones de inconstitucionalidad promovidas por la Audiencia Nacional, los dos fallos no unánimes del Tribunal Constitucional, $y$ un dispar, tardío e impugnado desarrollo reglamentario han jalonado un proceso que sólo concluyó a mediados de 1991, cuando la Sala Tercera del Tribunal Supremo - variando por imperativo de la Sa- 
la Especial del Tribunal Supremo su doctrina anterior- declaró ajustado a Derecho el Reglamento de la prestación social de los objetores de conciencia (aprobado por el Real Decreto 20/1988, de 15 de enero). Este insatisfactorio discurrir normativo ha provocado -como señala el profesor Millán Garrido- una situación de provisionalidad e inseguridad jurídica prolongada, al tiempo que ha impedido, al menos hasta la fecha indicada, la pacífica "aplicación integral del sistema legalmente establecido".

La Constitución española de 1978 dice expresamente que la objeción de conciencia es una de las causas de exención del servicio militar obligatorio (art. 30.2), pero lo que se hace necesario es precisar si, además, es un auténtico derecho. La cuestión, como es fácilmente imaginable, no es en absoluto baladí, sino que conlleva importantes consecuencias de todo orden. A pesar de la trascendencia de esta pregunta (¿es o no es un verdadero derecho?), la respuesta no ofrece demasiados problemas: estamos ante un auténtico derecho reconocido constitucionalmente. Diversos argumentos apoyan esta conclusión. En primer lugar, podemos acudir al llamado clásicamente argumento gramatical. En efecto, en favor de la tesis de que la objeción de conciencia es un derecho cabe aducir los términos utilizados en la redacción del inciso final del artículo 53.2 de la Constitución («Este último recurso será aplicable a la objeción de conciencia reconocida en el artículo $30 \%$ ), pues la fórmula "reconocida" es más propia de la proclamación de un derecho que del establecimiento de una mera exención a una obligación general. En segundo lugar, la circunstancia de que la objeción de conciencia, como hemos visto, esté protegida por el recurso de amparo, vía extraordinaria que está reservada exclusivamente para la tutela de los derechos fundamentales y las libertades públicas. En tercer lugar, confirma la consideración de que la objeción de conciencia al servicio militar es un auténtico derecho la rotunda doctrina del Tribunal Constitucional en este punto concreto. Así, en la Sentencia de 23 de abril de 1982, tras indicar que la objeción de conciencia constituye una especificación de la libertad de conciencia, afirma textualmente que "la objeción de conciencia es un derecho reconocido explícita e implícitamente en la ordenación constitucional española». Finalmente, en cuarto /ugar, para reafirmarnos en esta tesis no tenemos más que recordar las primeras palabras del artículo 1.1 de la Ley 48/1984, que expresa- 
mente aluden al "derecho a la objeción de conciencia reconocido en el artículo $\mathbf{3 0}$ de la Constitución". Con lo cual, como decíamos, no hay duda de que tanto los Constituyentes, como el legislador ordinario, como el Tribunal Constitucional consideran la objeción de conciencia no sólo una mera causa de exención del servicio militar obligatorio, sino también un verdadero derecho.

Uno de los puntos que mayor polémica ha suscitado el tema de la objeción de conciencia ha sido, sin duda, el de su naturaleza jurídica; concretamente, el de determinar si tiene categoría de derecho fundamental o si, por el contrario, es un simple derecho constitucional sin dicho rango.

En efecto, la cuestión de la naturaleza jurídica de la objeción de conciencia ha sido y, en alguna medida, sigue siendo objeto de profundas controversias en la doctrina. Controversias alimentadas por la -al menos en apariencia- titubeante jurisprudencia del Tribunal Constitucional en este punto.

1. Así, en la Sentencia $15 / 1982$, de 23 de abril, el Tribunal Constitucional pareció inclinarse bastante claramente por conceptuar la objeción de conciencia como un derecho fundamental.

2. Sin embargo, las dos importantísimas Sentencias del Tribunal Constitucional de 1987 (la 160/1987 —que resolvió el recurso de inconstitucionalidad interpuesto por el Defensor del Pueblo-y la 161/1987 — que resolvió las cuestiones de inconstitucionalidad promovidas por la Audiencia Nacional-) modificaron, o al menos matizaron muy sensiblemente, la jurisprudencia anterior. A juicio del Tribunal, «es justamente su naturaleza excepcional - derecho a una exención de un deber constitucional, como es el de la defensa de España-, lo que le caracteriza como derecho constitucional autónomo, pero no fundamental's.

La primera consecuencia de conceptuar el derecho a la objeción de conciencia al servicio militar como un iderecho constitucional autónomo, pero no fundamental», es que el legislador deberá regular este derecho a través de una ley ordinaria. En este sentido, el Tribunal Constitucional rechaza categóricamente que deba desarrollarse a través de una ley orgánica, como defendía el Defensor del Pueblo en su recurso de inconstitucionalidad y como planteaba como duda fundada la Audiencia Nacional en sus cuestiones de inconstitucionalidad. 
3. Por tanto, en síntesis, hemos pasado de una jurisprudencia del Tribunal Constitucional que parecía inclinarse por conceptuar el derecho a la objeción de conciencia al servicio militar como un derecho fundamental a otra que, claramente, lo caracteriza como un "derecho constitucional autónomo, pero no fundamental».

Cuando los autores reflexionan sobre el cambio de rumbo que ha experimentado la jurisprudencia del Tribunal Constitucional, suelen atribuirlo, por lo general, a la uexcesiva preocupación por los efectos prácticos que para las instituciones castrenses pudieran tener sus pronunciamientos" (Cámara Villar). El salto intelectual que da el Tribunal Constitucional entre las primeras sentencias y las últimas es muy sensible: el derecho a la objeción de conciencia queda despojado de la categoría de derecho fundamental - que hasta entonces parecía tener- y queda reducido a un "derecho constitucional autónomo", es decir - si se nos permite la expresión-, a un derecho de «segunda categoría». Este giro en la jurisprudencia del Tribunal Constitucional posiblemente requería de una mayor fundamentación, sobre todo si tenemos en cuenta que esta última interpretación de la objeción de conciencia se aparta, en no poca medida, del criterio mantenido por varios organismos internacionales.

Tras reiterar una vez más que la jurisprudencia del Tribunal Constitucional en el tema de la objeción de conciencia no ha sido plenamente satisfactoria, hay que añadir unas palabras en su descargo: la causa fundamental de que la jurisprudencia constitucional en esta materia sea vacilante (y de que aún pueda seguir siéndolo en el futuro) se debe en gran medida a la defectuosa constitucionalización de la objeción de conciencia, ambigua en los términos y forzadamente separada de la libertad ideológica y religiosa del artículo 16. Como afirma con razón el profesor Cámara Villar, «desde el momento constituyente se estaba ya escribiendo la crónica de una polémica anunciada".

Conviene precisar, antes de seguir adelante, que el artículo 30.2 de la Constitución no impone un deber genérico, que puede cumplirse bien con el servicio militar o bien con la prestación social sustitutoria a elección del interesado. Por el contrario, en nuestro ordenamiento constitucional existe un deber concreto de cumplir - cuando la ley lo indique - ciertas obligaciones militares. Sólo por serios motivos de 
conciencia, debidamente alegados y en cierta medida probados, se podrá eximir a los ciudadanos de este deber. Dicho con otras palabras, el servicio militar obligatorio y la prestación social sustitutoria, aunque ambos son deberes personales a favor de la comunidad, no son alternativos, sino - como indican los propios términos - el segundo es sustitutorio del primero. A pesar de que dudemos de la bondad de este sistema, creemos, con el profesor Llamazares Fernández, que "la correcta lectura del Texto Constitucional no admite otra interpretación».

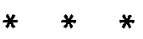

El segundo párrafo del artículo 30 de la Constitución señala que el derecho a la objeción de conciencia ha de ser desarrollado por el legislador ordinario "con las debidas garantías", expresión que ha provocado algunas discusiones en la doctrina sobre cuál sea su sentido constitucional.

El Tribunal Constitucional, en la Sentencia 161/1987, afirma que la expresión del artículo 30.2 "con las debidas garantías", que condiciona la regulación legal de la objeción de conciencia, debe entenderse referida no sólo a las garantías para el objetor, sino también a la comprobación de la alegada causa de exención y, asimismo, a las necesidades y buen funcionamiento de las Fuerzas Armadas, cuya relevancia constitucional está reconocida en el artículo 8 de la Constitución.

En síntesis, pues, "las debidas garantías" que debe adoptar el legislador han de ser entendidas en un doble sentido: por un lado, deben procurar impedir que la falsa alegación de la objeción de conciencia pueda emplearse como una vía fraudulenta para escapar de las obligaciones militares; y por otro, deben asegurar que el verdadero objetor verá reconocido su derecho, "sin restricciones injustificadas o desproporcionadas al mismo" (Eduardo Espín).

El segundo apartado del artículo 1 de la Ley 48/1984 indica cuáles son los motivos de conciencia que el legislador español considera relevantes para poder ser eximido de la obligación de prestar el servi- 
cio militar. Este precepto dice así: "Los españoles sujetos a obligaciones militares que, por motivos de conciencia en razón de una convicción de orden religioso, ético, moral, humanitario, filosófico u otros de la misma naturaleza, sean reconocidos como objetores de conciencia, quedarán exentos del servicio militar, debiendo realizar en su lugar una prestación social sustitutorian. Por tanto, se admiten expresamente cinco tipos de motivaciones (religiosas, éticas, morales, humanitarias y filosóficas) y se deja una cláusula abierta (otras motivaciones de la misma naturaleza) para garantizar - como dice el preámbulo de esta Ley- "la máxima amplitud" en cuanto a las causas de la objeción de conciencia. La relación de motivos que enumera el artículo 1.2 de la Ley 48/1984, directamente inspirada en la Resolución 337 de la Asamblea Consultiva del Consejo de Europa y en las legislaciones extranjeras más avanzadas, ha merecido elogios por su carácter amplio y abierto.

La doctrina, tradicionalmente, reconduce la diversidad de motivaciones a tres grandes grupos: religiosas, filosóficas y políticas. Nosotros, en nuestra exposición, seguiremos este esquema, incluyendo en el segundo grupo, cuando menos, los motivos que el artículo 1.2 de la Ley 48/1984 conceptúa de éticos, morales, humanitarios y filosóficos.

1. La objeción de conciencia por motivos religiosos es aquella oposición a cumplir el servicio militar o a intervenir en un conflicto bélico que se fundamenta en los preceptos de los textos que el sujeto en cuestión considera sagrados o en las interpretaciones de los mismos. El ciudadano que se ve envuelto en este conflicto de normas decide obedecer la norma religiosa y transgredir por tanto el mandato jurídico estatal, con el fin de asegurarse una recompensa eterna o evitar los castigos ultraterrenos que podría acarrearle actuar en contra de la ley divina.

En España, como hemos dicho, el fenómeno de la objeción de conciencia al servicio militar tiene sus primeras manifestaciones públicas a finales de los años cincuenta de este siglo, cuando varios ciudadanos pertenecientes a la comunidad religiosa de los testigos de Jehová se negaron a empuñar las armas, actitud que han venido manteniendo ininterrumpidamente hasta nuestros días. En cambio, hemos de esperar hasta enero de 1971 para que aparezca el primer objetor de conciencia católico, y sólo al comienzo de la transición política se produjeron las primeras declaraciones públicas de objeción de conciencia por motivos no religiosos.

En la actualidad, buena parte de los objetores de conciencia re- 
conocidos por el Consejo Nacional de Objeción de Conciencia son testigos de Jehová, y el número de objetores católicos, aunque todavía no es muy elevado, va en progresivo aumento.

2. La objeción de conciencia por motivos filosóficos, que conoció un importante auge a raíz de las dos Guerras Mundiales, protege "concepciones totalizadoras del mundo no basadas en religión alguna, pero susceptibles de imponer a quienes las sustentan obligaciones morales respecto de su comportamiento práctico" (García Morillo).

El artículo 1.2 de la Ley 48/1984, tras referirse a los motivos religiosos, alude a los de carácter "ético, moral, humanitario, filosófico u otros de la misma naturaleza", como jurídicamente relevantes para obtener una declaración favorable del Consejo Nacional de Objeción de Conciencia. A nuestro juicio, esta segunda parte de la fórmula utilizada por el legislador español podría simplificarse hablando simplemente de "motivos filosóficos", pues todos ellos son reconducibles a una valoración personal sobre el bien y el mal a partir de la propia escala de valores. Posiblemente, lo que pretende el legislador con esta segunda parte de la fórmula del artículo 1.2 de la Ley 48/1984 es reflejar diversos aspectos de una conciencia objetora sustancialmente idéntica.

La secularización creciente de la sociedad española en los últimos años también ha tenido su reflejo en este ámbito. Así, el número de objetores de conciencia que han invocado motivos filosóficos, totalmente desligados de cualquier confesión religiosa, ha experimentado un espectacular incremento desde comienzos de la década de los ochenta.

3. Los motivos de orden religioso y filosófico suelen estar recogidos, sin especiales dificultades, en la inmensa mayoría de ordenamientos que admiten la objeción de conciencia al servicio militar. Mayores problemas presenta, sin duda, aceptar como relevantes los motivos de orden político. En efecto, aunque algunas legislaciones (v. gr., las de Alemania, Noruega y Dinamarca) admiten indubitadamente las motivaciones políticas, son más frecuentes aquellas que las excluyen.

De forma aproximativa, podríamos decir que el objetor de conciencia por motivos políticos es aquella persona que se niega a realizar el servicio militar o a participar en una determinada guerra a partir de la valoración que hace de la situación política concreta.

Entre los casos más recientes y conocidos de objeción de conciencia política ejercida por un gran número de personas ante una de- 
terminada guerra, cabe citar a los franceses que se negaron a participar en la guerra de Argelia a principios de los años sesenta y a las decenas de miles de jóvenes norteamericanos que se negaron a combatir en la guerra del Vietnam. En otros casos, la objeción de conciencia por motivos políticos no está vinculada a una guerra en concreto, sino que quiere ser una protesta contra el sistema político-militar en su conjunto; éste sería el caso, por ejemplo, de los ciudadanos de algunos países europeos que alegaron objeción de conciencia porque su país seguía una determinada política de armamento nuclear o porque formaba parte del llamado "bloque capitalista".

Analizando el Derecho español vigente, lo primero que constatamos es que la fórmula que utiliza el artículo 1.2 de la Ley 48/1984 no se refiere expresamente a los motivos de orden político. Surge, por tanto, la siguiente pregunta: ¿están implícitamente incluidos los motivos políticos en la fórmula que consagra este precepto?; 0 , dicho con otras palabras, ¿puede ser reconocido como objetor de conciencia y, por tanto, quedar exento del servicio militar quien invoque una convicción de naturaleza política?

El tema de las motivaciones políticas como causa de la objeción de conciencia al servicio militar se ha planteado con especial complejidad en solicitudes de jóvenes independentistas de algunas nacionalidades históricas, especialmente vascos y catalanes. Asi, con cierta frecuencia, el Consejo Nacional de Objeción de Conciencia ha recibido solicitudes fundamentadas en que el peticionario no se consideraba ciudadano español y, por tanto, se negaba a cumplir el servicio militar en el ejército español, al que consideraba invasor de su patria, al tiempo que indicaba -expresa o tácitamente- que estaría dispuesto a cumplir sus obligaciones militares en el ejército de un hipotético Estado vasco o catalán. En otros casos, menos frecuentes, el solicitante invocaba como motivo de su negativa la actual organización y régimen interno de las Fuerzas Armadas o la incorporación de España a la estructura defensiva de la Alianza Atlántica.

Las solicitudes que han alegado alguna de estas razones, si no han incluido además uno o varios de los motivos legalmente reconocidos, han sido rechazadas por el Consejo Nacional de Objeción de Conciencia, quien ha resuelto declarando no haber lugar al reconocimiento de la condición de objetor.

Nosotros discrepamos de la posición del Consejo en este punto, pues - a nuestro juicio- los motivos de carácter político tienen, en la inmensa mayoría de los casos, entidad suficiente para fundamentar 
una resolución favorable del Consejo. Justificamos esta afirmación en base a los siguientes argumentos:

$\left.1.0^{\circ}\right)$ Entendemos que los motivos políticos pueden incluirse bien dentro de los motivos filosóficos o bien dentro de la cláusula abierta - «otros de la misma naturaleza»-con que concluye la fórmula del artículo 1.2 de la Ley 48/1984. En efecto, por lo que se refiere al motivo "filosófico", hay que señalar que es un término de tal amplitud que es capaz de abarcar a muchos otros que expresamente no figuran en la literalidad de la ley, y particularmente a aquellos que podríamos calificar de ideológicos o políticos, porque, como afirma el profesor Cámara Villar, "las ideas políticas son en un grado u otro expresión de una previa filosofía política». Además, y como apuntábamos hace un momento, también creemos que pueden incluirse los motivos políticos en la cláusula de apertura final, pues su naturaleza es -en muchos casos-similar a la de los motivos éticos, morales, humanitarios y filosóficos.

2..$^{\circ}$ Por otra parte, estimamos que es posible llegar a la misma conclusión (esto es, la validez de la objeción política) a partir de una reflexión sobre el fundamento de los motivos relevantes, ya que -según el propio preámbulo de la Ley 48/1984- ues la incompatibilidad entre las actividades militares y las convicciones del ciudadano, y no la naturaleza de dichas convicciones, lo que justifica la exención del servicio militar».

3. ) No consideramos aceptables las críticas que, a menudo, se dirigen contra los motivos políticos en el sentido de que son ocasionales y relativos, frente a los motivos religiosos y éticos, que serían permanentes y absolutos. No consideramos aceptables estas críticas, como decimos, porque, además de que los motivos religiosos y éticos no son siempre permanentes y absolutos, los motivos políticos pueden ser vividos por quien los invoca de forma permanente y con una gran convicción e intensidad.

Conviene precisar en este momento que el derecho a la objeción de conciencia no asegura la no incorporación a filas, sino sólo el examen del caso y una resolución sobre el mismo ajustada a Derecho. 
La solicitud de reconocimiento de la condición de objetor de conciencia debe dirigirse al Consejo Nacional de Objeción de Conciencia, que es el órgano competente para efectuar dicho reconocimiento.

El Defensor del Pueblo, en el recurso de inconstitucionalidad que interpuso contra la Ley 48/1984, impugnó, entre otros muchos aspectos, la necesidad de solicitar la declaración de objeción de conciencia ante el Consejo y la competencia de éste para el reconocimiento de la condición de objetor.

El Tribunal Constitucional afirma que "es verdad que es el objetor de conciencia, y sólo él, el que "declara", manifiesta o expresa su condición de objetor, es decir, su oposición al servicio militar por los motivos que le afecten en conciencia. Pero eso no basta para que, automáticamente, sin más, se le tenga por tal, pues el fuero de la conciencia ha de conciliarse con el fuero social o colectivo". En este punto estamos plenamente de acuerdo con la doctrina del Tribunal Constitucional, pues si el Consejo Nacional de Objeción de Conciencia tuviera que limitarse a tomar constancia de las peticiones recibidas -como parece sugerir el Defensor del Pueblo-, funcionaria como un simple registro de los individuos que se habrían autoconvertido para todos los efectos en objetores de conciencia; y con este sistema no habría forma alguna de adoptar las "debidas garantías" que exige imperativamente el artículo 30.2 de la Constitución.

El artículo 3.1 de la Ley 48/1984 exige que en el escrito de solicitud se hagan constar "los motivos de conciencia que se oponen al cumplimiento del servicio militar».

En nuestra opinión, este requisito es absolutamente lógico, pues - como ha indicado el Tribunal Constitucional- la objeción de conciencia es un derecho condicionado y de excepción, cuyo contenido consiste precisamente en eximir de las obligaciones militares. Las "debidas garantias" que exige la Constitución a la ley que regule la objeción de conciencia se refieren, en uno de sus aspectos, a la comprobación de que el solicitante alega uno o varios motivos de objeción legalmente relevantes y a que efectivamente se dan estos motivos en su fuero interno (es decir, alegación correcta y veracidad de las convicciones manifestadas); y ambas comprobaciones serían absolutamente imposibles si el peticionario no expusiera en su solicitud "los 
motivos de conciencia que se oponen al cumplimiento del servicio militarn. Por tanto, la pretensión de ser declarado objetor de conciencia por el Consejo conlleva una cierta carga probatoria para el solicitante, consistente en "acreditar la concurrencia de la condición prevista en la Ley para dar paso a la excepción" (Luis Prieto y Marina Gascón).

La doctrina, al estudiar la necesidad de alegar en la solicitud "los motivos de conciencia que se oponen al cumplimiento del servicio militar" (art. 3.1 de la Ley 48/1984), ha subrayado su posible contradicción con el artículo 16.2 de la Constitución, ya que, según el mismo, "nadie podrá ser obligado a declarar sobre su ideología, religión o creencias". La pregunta sobre la constitucionalidad o inconstitucionalidad de este precepto legal está presente, como decimos, en la inmensa mayoría de los trabajos doctrinales que abordan el estudio de esta temática.

El Tribunal Constitucional, en la Sentencia 160/1987 que resolvió el recurso de inconstitucionalidad interpuesto por el Defensor del Pueblo, afirmó que es perfectamente constitucional la exigencia legal de indicar en la solicitud los motivos de conciencia que se oponen al cumplimiento del servicio militar. "Por un lado - dice el Tribunal-, el legislador, la comunidad, no puede satisfacerse con la simple alegación de una convicción personal que, por excepcional, ha de ser contrastada para la satisfacción del interés común. De otro, el objetor, para la recognoscibilidad de su derecho, ha de prestar la necesaria colaboración si quiere que su derecho sea efectivo".

El segundo apartado del artículo 3 de la Ley 48/1984 -previendo que las alegaciones del objetor sean insuficientes, inconsistentes 0 contradictorias-introduce una polémica cláusula en los siguientes términos: «El Consejo podrá recabar de los interesados que, por escrito u oralmente, amplien los razonamientos expuestos en la solicitud. Podrá, igualmente, requerir de los solicitantes o de otras personas u organismos la aportación de la documentación complementaria o testimonios que se entiendan pertinentes". Este precepto también fue impugnado por el Defensor del Pueblo.

1. En cuanto a la presunta inconstitucionalidad de la facultad del Consejo para pedir al solicitante que amplíe los razonamientos que inicialmente expuso en la solicitud, el Tribunal Constitucional replicó 
diciendo que si la necesaria declaración del objetor no supone, como hemos visto, vulnerar ningún derecho, tampoco lo implicará la petición del Consejo dirigida al objetor para que amplie los razonamientos que expuso en su solicitud, ya que, razonablemente, cabe la posibilidad de una solicitud escueta, imprecisa, no razonada o contradictoria.

2. Mayores críticas de inconstitucionalidad ha recibido la facultad del Consejo para requerir de terceras personas u organismos la aportación de la documentación complementaria o testimonios que entienda pertinentes. Es lo que comúnmente se conoce como la "aportación externa" de documentos y testimonios.

El Defensor del Pueblo también impugnó este segundo inciso del artículo 3.2 de la Ley 48/1984, por entender que violaba el derecho a la intimidad personal reconocido en el artículo 18.1 de la Constitución. EI Tribunal Constitucional, sin embargo, rechazó de nuevo este reproche de inconstitucionalidad. Es cierto - dice el Tribunal- que "esa aportación externa de documentos y testimonios podría afectar a la intimidad o personalidad del objetor, en cuanto juicio ajeno a su conciencia o motivación para el ejercicio del derecho, pero también lo es que, aparte del interés general en la comprobación de la seriedad de los motivos, siempre cabrá al interesado la posibilidad de impugnar aquellos datos o la forma de obtenerlos e incluso ejercitar los pertinentes recursos, ante el propio Consejo, en forma de reclamaciones, o en vía jurisdiccional. En todo caso - sigue diciendo el Tribunal-, tal como se configuran las facultades del Consejo, que no puede "entrar a valorar las doctrinas alegadas por el solicitante" (art. 4.3 de la misma Ley), hay que entender que esa prueba que autoriza el inciso cuestionado ha de referirse, como es lógico, a hechos susceptibles de comprobación, a hechos externos constatables, no a la intimidad salvaguardada por el artículo 18 de la Constitución y garantizada por el recurso de amparo, sin que ello autorice a realizar pesquisas o investigaciones sobre la vida y conducta privada del objetor".

A pesar de esta rotunda declaración de constitucionalidad efectuada por el Tribunal Constitucional, la facultad del Consejo para pedir de terceras personas u organismos la aportación de datos sobre el ciudadano que quiere ser reconocido objetor de conciencia ha provocado serias críticas, tanto en los Votos Particulares de los magistrados Carlos de la Vega y Fernando García-Mon como en un importante sector de la doctrina científica.

A nuestro juicio, estamos, sin duda, ante uno de los aspectos más polémicos y problemáticos de la Ley, porque la potestad del Con- 
sejo para pedir a terceras personas u organismos informaciones o documentaciones relativas a la objeción de conciencia del solicitante roza claramente el derecho a la intimidad personal que reconoce el artículo 18.1 de la Constitución. Opinamos que hubiera sido más conveniente no atribuir esta facultad al Consejo, obligándole a decidir exclusivamente sobre los datos y documentos que el solicitante hubiera querido voluntariamente exteriorizar; y si éstos fueran insuficientes o contradictorios, incluso después de que el Consejo le pidiera que los ampliara, que se atuviera a las consecuencias, es decir, a una posible resolución denegatoria.

Sin embargo, aunque estimamos que la facultad del Consejo de poder acudir a esta "aportación externa" de datos es perturbadora e indeseable, coincidimos con el Tribunal Constitucional en el sentido de que - dentro de ciertos límites- no puede tacharse de inconstitucional. Tres razones permiten, en nuestra opinión, salvar su difícil constitucionalidad: en primer lugar, los estrechísimos márgenes en que el Tribunal Constitucional ha dejado reducida esta facultad indagatoria, ya que - como hemos visto- debe limitarse "a hechos susceptibles de comprobación, a hechos externos constatables, no a la intimidad", quedando prohibido "realizar pesquisas o investigaciones sobre la vida y conducta privada del objetor". En segundo lugar, la obligación de dar audiencia al solicitante siempre que haya habido una aportación externa de documentación complementaria o testimonios, "al objeto de no debilitar procedimentalmente su posición y equilibrar de esta manera la información sobre la que el Consejo formará sus juicios y determinará, por consiguiente, su resolución» (Cámara Villar). Por último, en tercer lugar, creemos que salva la constitucionalidad de esta facultad indagatoria la posibilidad que tiene el solicitante de impugnar -en vía administrativa, en vía judicial y en vía constitucional- las actuaciones del Consejo y los datos que haya obtenido vulnerando su derecho a la intimidad personal. Estas tres razones, como decimos, permiten -a nuestro juicio- afirmar la constitucionalidad del inciso final del artículo 3.2 de la Ley 48/1984, a pesar de que sería conveniente que el Consejo -salvo supuestos muy concretos y por razones muy fundamentadas - no hiciera uso de las facultades que el mismo le otorga. 
De acuerdo con el tercer apartado del artículo 1 de la Ley 48/1984, el derecho a la objeción de conciencia puede ejercerse hasta el momento en que se produzca la incorporación al servicio militar en filas $y$, una vez finalizado éste, mientras se permanezca en la situación de reserva. Por tanto, como vemos, el derecho a la objeción de conciencia puede ejercerse en dos períodos diferentes: el primero comienza el primer día del último trimestre del año en que se cumplen los diecisiete años de edad y concluye en el momento en que se produce la incorporación al servicio militar en filas; y el segundo período va desde que finaliza la fase de actividad del servicio militar hasta que concluye la situación de reserva, esto es, hasta el 31 de diciembre del tercer año posterior a la finalización del servicio militar. En consecuencia, queda tácitamente prohibida la denominada objeción de conciencia "sobrevenida", es decir, aquella cuyo reconocimiento pretende obtenerse durante la situación de actividad del servicio militar.

La prohibición de la objeción de conciencia sobrevenida ha sido, sin duda, uno de los puntos más polémicos y criticados de la Ley, pues excluye radicalmente la posibilidad de ejercer este derecho durante una etapa fundamental de la vida del ciudadano: el período de realización efectiva del servicio en filas. Las dudas sobre la constitucionalidad de esta exclusión radical han sido muy frecuentes en la doctrina, escuchándose a menudo preguntas del siguiente tenor: ¿por qué un ciudadano no puede llegar a ser - de manera sincera- un objetor de conciencia una vez incorporado al servicio militar en filas?, ¿hasta qué punto puede estimarse constitucional una norma que prohíbe totalmente ejercer el derecho a la objeción de conciencia durante la situación de actividad del servicio militar?, y ¿qué queda del derecho a la objeción de conciencia en este período?

La Sentencia del Tribunal Constitucional 161/1987, que resolvió las cuatro cuestiones de inconstitucionalidad promovidas por la Audiencia Nacional, declaró perfectamente constitucional la prohibición de la objeción de conciencia sobrevenida. Para llegar a esta conclusión, el Tribunal argumentó en un doble sentido:

1. ) En primer lugar, hizo una ponderación de todos los bienes jurídicos protegibles en juego. Dentro de esta necesaria ponderación, no le parece excesiva al Tribunal la restricción impuesta por el artículo 1.3. Ésta se justifica - a su juicio- en atención a la organización interna del servicio militar obligatorio y a la prestación de un deber constitucional cuya dimensión colectiva podría resultar perturbada por el ejercicio individual del derecho durante el período de incorporación a filas. 
2..$^{\circ}$ En segundo lugar, invocó la existencia de algunos ordenamientos jurídicos extranjeros democráticos y algunas declaraciones internacionales que no reconocen la objeción de conciencia sobrevenida.

Por todo ello, el Tribunal Constitucional concluye que "la examinada exclusión temporal del ejercicio del derecho de objeción de conciencia es razonable $y$ proporcionada a los fines que objetivamente persigue y no destruye o vulnera el contenido (esencial) del derecho constitucionalmente reconocido, por lo que el artículo 1.3 de la Ley $48 / 1984$ no es inconstitucional»".

A la Sentencia 161/1987 se formularon tres Votos Particulares. En ellos los cuatro magistrados discrepantes llegaron -aunque fuera por caminos intelectuales parcialmente diferenciados - a la misma conclusión: el fallo debió anular por inconstitucional el artículo 1.3 de la Ley $48 / 1984$, en cuanto excluye totalmente el ejercicio del derecho a la objeción de conciencia durante la fase de actividad del servicio militar.

A nuestro juicio, $y$ en esto coincidimos plenamente con los magistrados discrepantes y con la mayoría de la doctrina, el artículo 1.3 de la Ley 48/1984, al prohibir en todos los casos el ejercicio del derecho a la objeción de conciencia una vez incorporado a filas, es inconstitucional, pues no limita o restringe el derecho, lo cual seria admisible, sino que - como decimos- prohíbe absolutamente su ejercicio mientras dura la situación de actividad del servicio militar. Por ello, entendemos que el Tribunal Constitucional debió declarar su inconstitucionalidad.

En nuestra opinión, para afrontar y resolver el problema de la objeción de conciencia sobrevenida hay que partir de la existencia de un conflicto de intereses legítimos - el derecho del objetor a que se respete su derecho individual y la necesidad de garantizar la organización $y$ el buen funcionamiento de las Fuerzas Armadas-. Pero, a nuestro juicio, este conflicto no puede resolverse -como ha hecho el legislador español-suprimiendo uno de los dos polos del conflicto, sino ponderando real y efectivamente ambos bienes en juego. En efecto, es evidente que el bien constitucional de la defensa nacional y la protección de las Fuerzas Armadas encargadas de ella deben ser tenidos en cuenta al regular la objeción de conciencia sobrevenida. Por ello, creemos que sería conforme a la Constitución que el legislador, al igual que se ha hecho por ejemplo en la República Alemana, estableciese garantías reforzadas para el reconocimiento de la condición de objetor cuando el solicitante estuviera ya incorporado a filas, ya que las "debidas garantías" que exige la Constitución en el artículo 30.2 le autorizarían a incorporar estas mayores cautelas, en atención a los perjuicios que 
se ocasionarían a la organización militar con el reconocimiento de una objeción sobrevenida.

Entre estas "garantías adicionales» que podrían exigirse para reconocer la condición de objetor de conciencia a "los sobrevenidos" podemos pensar, siguiendo modelos extranjeros, en estas dos: primera, que sólo el reconocimiento del Consejo produjera la liberación del servicio militar y no la simple solicitud, por tanto, mientras se tramitase la solicitud del soldado objetor, debería seguir cumpliendo su servicio en filas; segunda, que se establecieran exigencias más rigurosas para que el Consejo pudiera reconocer la condición de objetor (por ejemplo, en cuanto a la seriedad del cambio, a la firmeza de las convicciones y a la prueba de las mismas). Este nuevo modelo, como es obvio, sería perfectamente constitucional, ya que -como reconoce el propio Tribunal Constitucional- la Constitución upermitía y permite al legislador otras opciones". La instrumentación técnica de este cambio legislativo sería muy sencilla, bastaría con modificar la redacción del artículo 1.3 de la Ley $48 / 1984$ y añadir un nuevo precepto en el que se especificasen las condiciones concretas para poder ejercer el derecho a la objeción de conciencia una vez incorporado al servicio militar en filas.

Con estas garantías adicionales se dificultaría razonablemente el ejercicio del derecho a la objeción de conciencia sobrevenida, pero no se negaría absolutamente su ejercicio, que es lo que hace en la actualidad el artículo 1.3 de la Ley 48/1984. Con lo cual se conseguiría armonizar, efectivamente, el respeto al derecho del objetor y la salvaguarda de la organización y el buen funcionamiento de las Fuerzas Armadas.

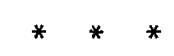

Pasando a otra cuestión, debemos indicar que la función más importante del Consejo Nacional de Objeción de Conciencia es la de conocer las solicitudes de reconocimiento de la condición de objetor de conciencia y resolver sobre las mismas. En efecto, tras la solicitud del interesado $y$, en su caso, la ampliación de los razonamientos expuestos en la solicitud y la aportación de documentación complementaria o testimonios a instancias del Consejo, éste debe resolver sin demora, declarando si ha lugar o no al reconocimiento de la condición de objetor de conciencia. 
- El Consejo dictará una resolución favorable al reconocimiento de la condición de objetor de conciencia solicitada cuando se cumplan estos dos requisitos: $1 .^{\circ}$ ) que el motivo o los motivos que se aleguen en la solicitud figuren entre los recogidos en el artículo 1.2 de la Ley 48/1984 (convicciones de orden religioso, ético, moral, humanitario, filosófico u otras de la misma naturaleza); y $22^{\circ}$ ) que, sobre la base de los datos e informes de que disponga, no perciba incongruencia entre los motivos y manifestaciones alegados por el solicitante y las conclusiones que se desprendan de las actuaciones obrantes en el expediente.

Aunque el Consejo deberá resolver todas las solicitudes que se le presenten $y$, en consecuencia, declarar haber lugar o no al reconocimiento de la condición de objetor de conciencia y a la consiguiente exención del servicio militar, el legislador se ha preocupado de precisar que si transcurren «seis meses desde la presentación de una solicitud sin que haya recaído resolución, aquélla se entenderá concedida". Con esta medida se pretende, esta vez de forma muy progresista, evitar que las dilaciones administrativas puedan perjudicar al ciudadano.

Los efectos de las resoluciones del Consejo que resuelven favorablemente las solicitudes de reconocimiento de la condición de objetor de conciencia son dobles: por una parte, la exención del servicio militar del objetor (tanto en tiempo de paz como en tiempo de guerra), quedando total y definitivamente desvinculado de las Fuerzas Armadas, bajo la calificación de "exento del servicio miliarn; y, por otra, la obligación de realizar, en su lugar, una prestación social sustitutoria.

- Se producirá una resolución del Consejo denegatoria de la solicitud de reconocimiento de la condición de objetor de conciencia cuando falte alguno de los dos requisitos que, como hemos estudiado, son necesarios para dictar una resolución favorable. Por tanto, se dictará una resolución denegatoria en los siguientes casos:

$\left.1 .^{\circ}\right)$ Cuando el motivo o los motivos que se aleguen en la solicitud no figuren entre los recogidos en el artículo 1.2 de la Ley 48/1984. Esta causa de denegación de la solicitud se daría, por ejemplo, cuando el solicitante alegara como motivo para no querer cumplir el servicio militar la dureza física que comporta, que es una pérdida de tiempo, que es un período de la vida en el que no se aprende nada positivo, que le aleja de sus seres queridos, que es una traba para su carrera profesional, que supone una pesada carga económica para su familia, etc. 
En todos estos casos, y otros muchos parecidos que podríamos imaginar, faltaria el primero de los requisitos.

2. ) Cuando, sobre la base de los datos e informes de que disponga el Consejo, perciba incongruencia entre los motivos y manifestaciones alegados por el solicitante y las conclusiones que se desprendan de las actuaciones obrantes en el expediente. Con este examen de la congruencia se busca - aunque sea con grandes limitaciones de diversa naturaleza - comprobar la sinceridad de las convicciones manifestadas. Esta causa de denegación de la solicitud se daría, por ejemplo, cuando el solicitante en el momento de ser llamado a filas estuviera prestando sus servicios como mercenario en el ejército de un país extranjero, cuando hubiera hecho recientemente una pública defensa del servicio militar obligatorio, o cuando se declarara Testigo de Jehová y los representantes de dicha confesión le negaran esta condición. En estos casos, y otros similares, faltaría el segundo de los requisitos.

Desde su puesta en funcionamiento en 1985, el Consejo Nacional de Objeción de Conciencia se ha ganado una justificada fama de ubenevolente" en la resolución de las solicitudes de reconocimiento de la condición de objetor de conciencia, ya que basta invocar - formalmente- uno de los motivos que señala el artículo 1.2 de la Ley 48/1984 (religioso, ético, moral, humanitario, filosófico u otros de la misma naturaleza) para que, sin exigencia de mayores aclaraciones y sin ningún tipo de indagación, se reconozca la condición de objetor de conciencia solicitada. ¡Es prácticamente imposible dar mayores facilidades!

A pesar de esta extrema generosidad, el Consejo ha denegado cierto tipo de solicitudes. Las principales causas de este rechazo han sido las siguientes: invocar motivos personales (deseo de no alejarse de la familia, desagrado por las tareas militares, etc.); invocar motivos profesionales ("me impediría hacer tal o cual oposición" o "acceder a tal o cual puesto de trabajo"); que la solicitud la haya formulado el padre en nombre de su hijo (en ocasiones recién nacido); que el solicitante afirme que, al ser el servicio militar y la prestación social sustitutoria opciones libremente elegibles, él opta por la segunda; que la solicitud se presente mientras se está cumpliendo la fase de actividad del servicio militar (la denominada uobjeción de conciencia sobrevenida"); no tener la edad adecuada para poder ser reconocido objetor; que la solicitud la formule una mujer (ya que no está sujeta al servicio militar obligatorio); y que el solicitante invoque motivos políticos puros. Aun cuando en principio proceda denegar la solicitud formulada, si existe alguna duda - por mínima que ésta sea- el Consejo pide al solicitante que amplíe y concrete los motivos por los que quiere ser re- 
conocido objetor, con el fin de que no se produzca ningún rechazo por desconocimiento de las razones admisibles o por deficiencias formales en la presentación de la solicitud.

Una cuestión que ofrece un indiscutible interés es la de si debe reconocerse o no la condición de objetores de conciencia a aquellos solicitantes que expresamente indican en su escrito de petición que no cumplirán la prestación social sustitutoria. La posición de algunos autores es que deberían denegarse estas solicitudes, ya que, al contener una cláusula en la que se expresa la voluntad de desobedecer la ley, son peticiones viciadas. Por el contrario, el Consejo Nacional de Objeción de Conciencia las ha admitido si han invocado un motivo legalmente adecuado. Entiende el Consejo que, si la solicitud contiene uno de los motivos que reconoce el artículo 1.2 de la Ley 48/1984, lo añadido (esto es, la declaración de voluntad de no querer cumplir la prestación social sustitutoria) es como si no se hubiera puesto, pues no afecta al núcleo del cometido del Consejo: que es declarar si procede o no reconocer la condición de objetor de conciencia. Así, en la práctica, en estos casos se resuelve favorablemente la petición de reconocimiento de la condición de objetor, pero se le advierte que queda obligado a cumplir la prestación social sustitutoria. Si al ser llamado se niega efectivamente a cumplir el servicio sustitutorio, sin dejar de tener la condición de objetor de conciencia, incurrirá en un delito contra el deber de cumplir la prestación social sustitutoria.

El artículo 30.2 de nuestra Constitución reconoce el derecho a la objeción de conciencia como causa de exención del servicio militar obligatorio, indicando que la ley puede «imponer, en su caso, una prestación social sustitutoria". Ésta ha sido regulada básicamente en el capítulo II (arts. 6 a 12) de la Ley 48/1984, de 26 de diciembre, reguladora de la objeción de conciencia y de la prestación social sustitutoria, y en el Real Decreto 266/1995, de 24 de febrero, por el que se aprueba el Reglamento de la objeción de conciencia y de la prestación social sustitutoria (que deroga el Real Decreto 20/1988, de 15 de enero, que fue el primer Reglamento de la prestación social sustitutoria).

Quienes sean declarados objetores de conciencia estarán exentos del servicio militar y quedarán obligados a realizar una prestación social sustitutoria consistente en actividades de utilidad pública que no 
requieran el empleo de armas ni supongan dependencia orgánica de instituciones militares. Esta radical y absoluta separación de la prestación social sustitutoria en relación con las estructuras militares nos parece un dato positivo, que no se da en todas las legislaciones. La prestación social sustitutoria "evita que la objeción de conciencia se convierta en una inadmisible excepción al cumplimiento de un deber en términos generales y absolutos, para serlo tan sólo en términos relativos a una de sus formas, respetándose, por una parte, las exigencias de la libertad de conciencia, así como los requerimientos del principio de igualdad de todos los ciudadanos ante la ley" (Cámara Villar).

La prestación social sustitutoria es, en el caso de los objetores de conciencia al servicio militar, una forma de cumplir el deber de defender a España, que tampoco excluye la necesidad, en su caso, de cumplir con otras obligaciones para con la defensa de España, con las que coexiste. Se trata de un deber de naturaleza semejante y contenido equivalente al servicio militar $y$, por ello, puede tener carácter sustitutorio. A mi juicio, no cabe duda de que todas las formas de prestación social sustitutoria son manifestaciones del deber general de defender a España. En la misma línea se expresaba el magistrado Carlos de la Vega Benayas en su Voto Particular a la Sentencia 160/1987, al afirmar que la prestación social "es una sustitución del servicio, un cambio o alteración de la forma del derecho y el deber de defender a Españan. Y añadía este magistrado: el servicio militar y la prestación social sustitutoria "son supuestos diferentes en la materialidad de su contenido, pero análogos en cuanto ambos son, en su especie, una manifestación del deber general de servir a España». Como afirma certeramente el profesor Cámara Villar, "el objetor reconocido como tal ha quedado exento de realizar el servicio militar, no de defender a Españan.

De acuerdo con el artículo 6.2 de la Ley reguladora de la objeción de conciencia, el Consejo de Ministros determinará los sectores en que se desarrollará la prestación social sustitutoria, señalándose como prioritarios los siguientes:

a) Protección civil.

b) Conservación del medio ambiente, mejora del medio rural y protección de la naturaleza.

c) Servicios sociales $y$, en particular, los que afecten a la acción comunitaria, familiar, protección de menores y adolescentes, tercera edad, minusválidos, minorias étnicas, prevención de la delincuencia y reinserción social de alcohólicos, toxicómanos y ex-reclusos. 
d) Servicios sanitarios.

e) Programas de cooperación internacional.

f) Cualesquiera otras actividades, servicios u obras de carácter análogo que sean de interés general.

Como vemos, las actividades en que consistirá la prestación social sustitutoria son, en tiempo de paz, tan duras como las militares. Sin embargo, los trabajos y funciones que se asignen a los objetores no pueden incidir negativamente en el mercado de trabajo. En tiempo de guerra, la prestación social sustitutoria consistirá necesariamente en el desarrollo de actividades de protección y defensa civil.

La prestación social sustitutoria se realizará preferentemente en entidades dependientes de las Administraciones Públicas. Sin embargo, también podrá cumplirse en entidades no públicas, que determinará el Ministro de Justicia, siempre que reúnan las siguientes condiciones:

a) Que no tengan fines lucrativos.

b) Que sirvan el interés general de la sociedad, en especial en los sectores sociales más necesitados.

c) Que no favorezca ninguna opción ideológica o religiosa concreta. La Oficina para la Prestación Social Sustitutoria ha hecho, a mi juicio de una forma muy elogiosa, una interpretación restrictiva de esta limitación, entendiendo que la prohibición no se refiere a la asociación matriz $-v$. gr., la Iglesia Católica o el sindicato UGT-, sino a la actividad concreta que realiza el objetor. Es decir, la actividad social del objetor no podrá favorecer a ninguna opción ideológica o religiosa concreta, aunque sí que es posible que esta actividad social esté organizada o dependa orgánicamente de alguna confesión o grupo ideológico concreto. Así, por ejemplo, se ha entendido que el colaborador social puede cumplir su prestación en Cáritas -institución dependiente de la Iglesia Católica-, ya que en ella el objetor puede cumplir neutralmente su función (en este sentido, cuando se reparten alimentos, se ayuda a toxicómanos o a personas desvalidas no se exige el bautismo a los beneficiados por esta actividad de Cáritas).

El régimen de la prestación social sustitutoria se estructura en forma semejante al servicio militar, comprendiendo por tanto las situaciones de disponibilidad, actividad y reserva. La disposición adicio- 
nal decimotercera, punto 3, de la Ley Orgánica 13/1991, del Servicio Militar, ha modificado el artículo 8.3 de la Ley 48/1984, al cual le ha dado la siguiente redacción: "La duración de la situación de actividad será fijada por el Gobierno mediante Real Decreto. En todo caso, comprenderá un período de tiempo que no será inferior a trece meses ni superior a dieciocho". El Gobierno, con buen criterio, ha fijado el plazo en el límite más bajo posible, esto es, trece meses (Real Decreto 525/1992, de 22 de mayo).

El Defensor del Pueblo, en el recurso de inconstitucionalidad que interpuso contra la Ley 48/1984, planteó tres posibles motivos de inconstitucionalidad en relación al artículo 8.3 de dicha Ley. En concreto, los siguientes:

1.') La posible inconstitucionalidad de someter la prestación social sustitutoria a un "régimen análogo" al establecido para el servicio militar.

$2 .^{\circ}$ La posible inconstitucionalidad de la mayor duración de la fase de actividad de la prestación social sustitutoria que la del servicio militar (ahora trece meses frente a nueve del servicio militar obligatorio).

3. ${ }^{\circ}$ La posible inconstitucionalidad de que se deje en manos del Gobierno la fijación de la duración concreta de la prestación social sustitutoria.

El Tribunal Constitucional, como es sabido, rechazó estos tres motivos de inconstitucionalidad, aceptando plenamente la regulación efectuada por el legislador ordinario. A mi juicio, dentro de ciertos limites, puede aceptarse la interpretación del Tribunal por lo que se refiere al punto primero y tercero, pero no en cuanto al segundo. Es decir, en mi opinión, la mayor duración de la prestación social sustitutoria que la del servicio militar es claramente inconstitucional por vulnerar el principio de igualdad, y así debió declararlo el Tribunal Constitucional. Tres magistrados del Tribunal, a través de sus votos particulares, y la mayoría de la doctrina, a través de sus artículos y libros, también han mantenido la inconstitucionalidad de esta desigual duración. A mi juicio, sería muy deseable que el legislador, a través de una reforma normativa, o el Tribunal Constitucional, mediante un cambio jurisprudencial, eliminaran esta desigual duración del servicio militar y la prestación social sustitutoria. 


\section{EL FUTURO DE LA OBJECIÓN DE CONCIENCIA AL SERVICIO MILITAR}

En España, uno de los temas que más polémica viene suscitando en los últimos años es, precisamente, el del futuro del servicio militar $y$, en consecuencia, de la objeción de conciencia al mismo. La situación actual es vista como insatisfactoria tanto por los jóvenes como por numerosos juristas. En efecto, con independencia de que en su momento la Ley $48 / 1984$ tuviera muchos aspectos positivos, ha sido rápidamente desbordada por las exigencias de la sociedad española, que en estas materias es una de las más progresistas de Europa.

Como afirmaba la Exposición de Motivos de la Proposición de Ley reguladora de la objeción de conciencia y de la prestación social presentada al Congreso de los Diputados por el Grupo Parlamentario Catalán (Convergència i Unió) el 28 de mayo de 1996: la aplicación de la Ley 48/1984, de 26 de diciembre, ha puesto en evidencia sus insuficiencias y limitaciones. El rechazo social y político ha sido, desde el mismo momento de su aprobación, muy importante. El recurso de inconstitucionalidad interpuesto por el Defensor del Pueblo, las cuestiones de inconstitucionalidad promovidas por la Audiencia Nacional, los dos fallos no unánimes del Tribunal Constitucional, un tardío e impugnado desarrollo reglamentario, la amplia oposición de la práctica totalidad del movimiento juvenil, la existencia de presos de conciencia por conntravenir la legislación vigente y las diversas iniciativas parlamentarias en esta materia, son elementos que han llevado al ánimo de las principales fuerzas políticas la necesidad de plantear un cambio sustancial en la actual normativa. La valiente Resolución del Parlamento Europeo Bandres-Bini, de enero de 1994, y la voluntad de avanzar hacia un modelo de Fuerzas Armadas totalmente profesionalizadas, son el camino que a mi juicio- deberán seguir los legisladores españoles.

Pero esto no es todo. En el momento de terminar de redactar estas líneas (marzo de 1998), ya es prácticamente segura la pronta profesionalización completa del Ejército. Concretamente, la fecha del 1 de enero del año 2003 es la propuesta sobre la que trabaja el Gobierno del Partido Popular. Con ello, habremos pasado de un modelo de recluta universal a otro modelo de Ejército basado exclusivamente en el voluntariado. Por lo que ahora a nosotros nos interesa, la consecuencia del cambio será que el tema de la objeción de conciencia al servicio militar tal como hoy lo entendemos habrá desaparecido por completo, si bien quedará el caso - ciertamente muy limitado- de la objeción de conciencia del soldado profesional. 
La reforma de la Ley de objeción de conciencia de 1984 planteada por la indicada Proposición de Ley del Grupo Parlamentario Catalán (Boletín Oficial de las Cortes Generales, Congreso de los Diputados, VI Legislatura, Serie B: 10 de junio de 1996, Núm. 36-1) se está tramitando con extrema lentitud debido a las diferencias que en este punto separan al Partido Popular y a sus socios nacionalistas. Esta circunstancia se ve agravada por el creciente número de objetores de conciencia y de insumisos, y por la certeza de que estamos en los últimos años de un modelo de recluta universal que la sociedad española en su inmensa mayoria rechaza.

A mi juicio, la solución pasa efectivamente por la total profesionalización de las Fuerzas Armadas. La sociedad española siente el servicio militar obligatorio como una carga inútil y reaccionaria, y no hay forma de lograr un Ejército eficaz sin convicción y sin profesionalidad. No son necesarios un millón de hombres reclutados a la fuerza y sin experiencia, basta con ciento cincuenta mil que hagan de la defensa nacional su oficio y su vocación: no olvidemos que hemos pasado de la guerra del máuser y la lata de sardinas a la guerra por ordenador. Por tanto, coincido con la propuesta del Grupo Popular - y ahora también de los demás grupos parlamentarios- de profesionalizar todo el Ejército.

Ahora bien, no puedo menos que estimar desafortunado el anuncio de que este cambio se producirá en el año 2003, pues todos los jóvenes que en estos últimos años tengan que cumplir el servicio militar o la prestación social sustitutoria tendrán la sensación -muy justificada- de ser los últimos paganos de un sistema en el que ya nadie cree y que está en franca liquidación. Además, la desaparición de la mili a plazo fijo engendrará, en un pueblo como el nuestro, toda una picaresca encaminada a retrasar unos años la incorporación a filas, para ver si es posible llegar al mítico 2003 y así quedar libre de cualquier obligación. Hubiera sido más conveniente anunciar la desaparición del servicio militar obligatorio y, por tanto, también de la prestación social sustitutoria en el momento en que - técnica y presupuestariamente- ya hubiera sido posible llevarla a cabo, y no con seis años de antelación.

Esta es mi opinión como ciudadano. Pero, como he dicho, otro es el camino que siguen los legisladores españoles, ya que - mientras se llega a la plena profesionalización del Ejército- se plantea la reforma de la Ley 48/84, que regula la objeción de conciencia y la prestación social sustitutoria. En esta labor, como constitucionalista y como estudioso de estos temas, me atrevo a formular las siguientes sugerencias: 
1. Igualar la duración de la prestación social sustitutoria con la del servicio militar. En la actualidad, como es sabido, la prestación sustitutoria dura cuatro meses más que el servicio de armas (trece frente a nueve), vulnerando claramente el principio de igualdad que consagra el artículo 14 de la Constitución. La mayor duración de la prestación social sustitutoria con respecto al servicio militar la justifica, el preámbulo de la Ley, diciendo que este último tiene unos costes personales y físicos superiores a aquélla. A mi entender, este argumento no es de recibo, pues prestar servicios en el cuerpo de lucha contra incendios, en el tercer mundo, en la recuperación de toxicómanos o en la asistencia a minusválidos o a enfermos del S.I.D.A. puede ser mucho más penoso que el cumplimiento de un servicio militar de utilidad bastante dudosa. En mi opinión, en esta mayor duración lo que hay, de forma encubierta y no confesada, es una sanción contra aquellos jóvenes que, por motivos de conciencia, se niegan a empunar las armas.

Por lo que se refiere a la posibilidad de reformar este punto, parece que las diversas fuerzas parlamentarias han llegado a un acuerdo, en el sentido de igualar la duración de la fase de actividad del servicio militar y la de la prestación social sustitutoria en nueve meses. Como es obvio, a quienes estén cumpliendo la prestación social en el momento de la aprobación de la nueva ley, les será de aplicación la reducción del período de actividad y las demás ventajas que puedan derivarse de ella.

2. Admitir los motivos políticos como relevantes para lograr el reconocimiento de la condición de objetor de conciencia. La actual Ley sólo admite los motivos religiosos, éticos, morales, humanitarios, filosóficos u otros análogos, excluyendo las razones de orden político, es decir, aquellas que se oponen a una cierta guerra o a un determinado Ejército. Es el caso de numerosos jóvenes independentistas que han alegado que no se consideran ciudadanos españoles y, por lo tanto, se niegan a cumplir el servicio militar en el Ejército español, al que consideran invasor de su patria, al tiempo que indican que estarian dispuestos a cumplir sus obligaciones militares en el Ejército de un hipotético Estado catalán o vasco.

A mi juicio, sería deseable que la futura ley admitiera las motivaciones de naturaleza política, pues no difieren sustancialmente de las de tipo filosófico y su exclusión viola posiblemente la libertad de conciencia reconocida en el artículo 16 de la Constitución. Además, la exclusión de los motivos políticos es una de las principales causas de enfrentamiento de la Administración con los movimientos de objetores 
de signo nacionalista. Tampoco preveo grandes dificultades para llegar a un acuerdo parlamentario sobre este extremo.

3. Aceptar la objeción de conciencia sobrevenida. De acuerdo con la Ley actual, el derecho a la objeción de conciencia puede ejercitarse en dos momentos: hasta que se produzca la incorporación al servicio militar en filas $y$, una vez finalizado éste, mientras se permanezca en la situación de reserva. Pues bien, en mi opinión, también debería aceptarse la objeción de conciencia sobrevenida, es decir, aquélla cuyo reconocimiento pretende obtenerse durante la situación de actividad del servicio militar. La actual regulación, so pretexto del buen orden militar, excluye radicalmente la posibilidad de ejercer este derecho durante una etapa fundamental de la vida del ciudadano: el período de realización efectiva del servicio en filas, que es precisamente cuando se conoce in situ lo que es la vida militar.

La Proposición de Ley presentada por Convergència i Unió permitía expresamente la objeción de conciencia sobrevenida (art. 1.3) y establecía su régimen jurídico (art. 2.3: «Si la declaración de objeción de conciencia se presenta durante el cumplimiento del servicio militar, se producirá baja automática del servicio en filas en el momento en que dicha declaración sea admitida por el Consejo. Si en el plazo de quince días desde la presentación de la declaración el interesado no hubiera recibido notificación alguna, causará baja del servicio. El tiempo transcurrido en filas se computará a efectos del tiempo de prestación social»). Sin embargo, como era previsible, ha sido ésta una materia innegociable para el Partido Popular. Como señala José L. Lobo, el Gobierno considera que admitir la objeción de conciencia sobrevenida "podría perturbar gravemente el proceso de profesionalización de las Fuerzas Armadas, ya que el Ministerio de Defensa no sabría de antemano cuántos jóvenes de cada reemplazo se declararían objetores tras llegar a los cuarteles, lo que obligaria a rellenar los huecos con llamamientos suplementarios». También traen a colación el viejo argumento de que las convicciones religiosas o filosóficas que pueden justificar la objeción de conciencia no surgen de la noche a la mañana. Por tanto, parece claro que -a menos que se produzca un improbable giro parlamentario de última hora-seguirá sin admitirse la objeción de conciencia sobrevenida.

4. Suprimir la facultad del Consejo Nacional de Objeción de Conciencia de pedir a terceras personas u organismos informes o documentos sobre la veracidad de las convicciones del objetor. Esta potestad del Consejo, que nos recuerda el informe de buena conducta del cura párroco o del cabo de la Guardia Civil de otras épocas, vulnera el derecho a la intimidad personal que reconoce el artículo 18.1 de la 
Constitución. Hemos de afirmar solemnemente que nadie puede entrar a valorar la conciencia de otra persona. No cremos que sea difícil llegar a un acuerdo sobre este punto.

5. Llamar a las mujeres a cumplir el servicio militar o la prestación social sustitutoria. Recuerdo, para evitar confusiones, que mi opción es que desaparezca el servicio militar obligatorio. Sin embargo, mientras que los legisladores mantengan el sistema de recluta universal, me parece una inadmisible vulneración del principio de igualdad que los varones tengan que cumplir el servicio militar y las mujeres no. Máxime teniendo en cuenta que las mujeres pueden incorporarse al Ejército como profesionales, es decir, cobrando, y en cambio están libres de aquella obligación cuando es a título gratuito. La Constitución encomienda la defensa de España a los "españoles" (sin distinguir entre hombres y mujeres), por lo que - a mi juicio- esta distinción hecha por el legislador ordinario es inconstitucional.

Aunque creo honradamente que mi argumento es irrefutable, no tengo la menor duda de que esta cuestión será omitida por todos los grupos parlamentarios. El peso de la tradición y comprensibles razones de oportunidad política, harán que se pase de puntillas sobre un tema tan espinoso. A un parlamentario que le comente esta posibilidad, me contestó: jsólo faltaría eso, bastantes problemas tenemos con el servicio militar de los hombres para meternos con el de las mujeres!

6. Descentralizar la oferta de plazas para cumplir la prestación social sustitutoria.Teniendo en cuenta que la Proposición de Ley que se está tramitando fue presentada por el Grupo Parlamentario de Convergència i Unió, no es de extrañar que se haya puesto el acento en que las comunidades autónomas puedan ejercer competencias importantes en el ámbito de la prestación social. En efecto, en dicha Proposición de Ley se establece que, mediante la formalización de convenios, las comunidades autónomas y los ayuntamientos colaborarán en la gestión y en la inspección de la prestación social sustitutoria, aunque oficialmente estas funciones sólo correspondan al Ministerio de Justicia. Se establece, asimismo, que este Ministerio y las comunidades autónomas que hayan asumido la gestión y la inspección de la prestación social sustitutoria han de celebrar reuniones, como mínimo, dos veces cada año para coordinarse y colaborar entre sí. En coherencia con todo ello, la Proposición de Ley también especifíca que el Gobierno aprobará en los próximos Presupuestos Generales del Estado las modificaciones de crédito necesarias para el desarrollo de los convenios, con el fin de dotar a las comunidades autónomas de los medios adecuados para poder desarrollar sus funciones y servicios. 
De momento, la única atribución que sigue vedada a las comunidades autónomas es la participación directa en el Consejo Nacional de Objeción de Conciencia, que, por otra parte, ve muy menguadas sus tradicionales competencias.

7. Reducir la duración del plazo para obtener el reconocimiento de la condición de objetor de conciencia. Con buen criterio, la futura ley está decidida a acortar la duración de alguno de los plazos administrativos que afectan al objetor de conciencia. Así, establece que el Consejo Nacional de Objeción de Conciencia sólo dispondrá de un plazo de tres meses (actualmente son seis) para resolver la solicitud de reconocimiento de la condición de objetor; transcurrido el cual sin que haya recaído resolución, aquélla se entenderá concedida (silencio positivo).

8. Reducir el tiempo de disponibilidad de los objetores de conciencia. La Proposición de Ley que se está tramitando también reduce sensiblemente la duración de la situación de disponibilidad del objetor, entendiendo por tal el tiempo que va desde que el declarante obtiene la certificación de objetor del Consejo hasta que inicia la situación de actividad (descontando, en su caso, el tiempo durante el cual el objetor está en situación de prórroga). Aunque el PSOE, IU, el PNV y los diputados del Grupo Mixto proponen que el tiempo de disponibilidad -es decir, de espera de destino- se reduzca a un año, previsiblemente los votos del PP, ClU y CC conseguirán que se prolongue por tres años, para equipararlo de esta manera al período de disponibilidad de los jóvenes que hacen el servicio militar.

Se trata de una cuestión de gran trascendencia práctica, pues en la actualidad hay cerca de 125.000 objetores que esperan adjudicación de destino, $y$ que el plazo de disponibilidad se cifre en uno o tres años hace variar muy sensiblemente el número de objetores que se verán libres de realizar cualquier prestación. La avalancha de peticiones de objeción (más de medio millón desde 1985) ha desbordado a la Administración, que durante todos estos años ha sido incapaz de ofrecer destino a un contingente tan numeroso de objetores. Ni siquiera los convenios firmados entre el Ministerio de Justicia y algunas comunidades autónomas han conseguido poner fin al colapso. Como ejemplo, basta de recordar que incluso con un plazo de disponibilidad de tres años, unos 25.000 jóvenes se verán "amnistiados" de cumplir la prestación social sustitutoria, pasando directamente a la situación de reserva.

9. Otorgar a los sindicatos facultades para intervenir en la diferenciación entre actividades correspondientes a la prestación social y 
los puestos que deben quedar para el mercado de trabajo. Con más buena voluntad que otra cosa, la actual Ley 48/1984 indica que, a los objetores de conciencia, se les «asignarán trabajos y funciones de tal manera que no se incida negativamente en el mercado de trabajo" (art. 6.3). Cumplir esto es casi imposible, pues prácticamente todas las actividades que realizan los objetores son trabajos que podrian desarrollarse perfectamente bajo un régimen contractual. Sin embargo, hay que poner limites para evitar posibles abusos por parte de la Administración y de las entidades colaboradoras (vg. suprimir un puesto de trabajo existente para situar en el mismo a un colaborador social que lo realiza gratuitamente). Por ello, me parece acertada la propuesta del Grupo Parlamentario de Convergència i Unió de que los sindicatos intervengan, mediante comisiones de seguimiento, en la diferenciación entre las actividades correspondientes a la prestación social y los puestos que deben quedar libres para el mercado de trabajo. Con este objetivo, parece correcta la inclusión de un representante de las centrales sindicales más representativas en el Consejo Nacional de Objeción de Conciencia.

10. Suprimir la pena de cárcel para los insumisos, tanto si lo son al servicio militar como si lo son a la prestación social sustitutoria. Enviar a prisión a jóvenes por actitudes que dentro de tres o cuatro años ya serán totalmente lícitas, repugna ampliamente a la conciencia social. Por ello, mientras se termina de liquidar el Ejército de recluta universal, pienso que deberían suavizarse las penas para aquellos objetores que sigan el camino de la insumisión. Éste es también el planteamiento que anida en la Proposición de Ley Orgánica que el PP, CIU y CC presentaron a principios de febrero de 1998 con el propósito de modificar el Código Penal. El objetivo es que los insumisos dejen de ser castigados con penas de cárcel (de seis meses a dos años) y de multa.

Sin embargo, como no podía ser de otro modo mientras aún no esté totalmente implantado el Ejército profesional, la insumisión seguirá siendo un delito, aunque con una pena mucho más suavizada. En efecto, la única pena que recaerá sobre los insumisos, como también ocurre en la actualidad, será la de inhabilitación. Dicho con otras palabras, quienen rehúsen realizar el servicio militar y la prestación social sustitutoria no podrán, mientras dure la condena, acceder a un puesto de trabajo en la Administración, ni desempeñar un cargo público, ni obtener becas o subvenciones del Estado. Con todo, estas penas también serán rebajadas: mientras que el Código Penal vigente fija una pena de ocho a doce años de inhabilitación absoluta para los objetores de conciencia que se nieguen a cumplir la prestación social sustitutoria, y 
de diez a catorce años para los jóvenes que se nieguen a cumplir el servicio de armas, la Proposición de Ley Orgánica presentada por los grupos parlamentarios que dan apoyo al Gobierno limita la inhabilitación a un plazo de entre cuatro y seis años.

A partir de la entrada en vigor de esta nueva norma, como señala José L. Lobo, ningún insumiso al servicio militar o a la prestación social sustitutoria ingresará ya en prisión, y quienes actualmente cumplen penas privativas de libertad - cerca de un centenar, la mayoría de ellos en régimen abierto- serán automáticamente excarcelados. 